\title{
Diurnal Effects of Regional Soil Moisture Anomalies on the Great Plains Low-Level Jet
}

\author{
MATTHEW A. CAMPBELL \\ Department of Atmospheric and Environmental Sciences, University at Albany, \\ State University of New York, Albany, New York \\ Craig R. Ferguson And D. Alex Burrows \\ Department of Atmospheric and Environmental Sciences, and Atmospheric Sciences Research Center, \\ University at Albany, State University of New York, Albany, New York
}

MARK BEAUHARNOIS

Atmospheric Sciences Research Center, University at Albany, State University of New York, Albany, New York

\section{GENG XIA}

Department of Atmospheric and Environmental Sciences, and Atmospheric Sciences Research Center, University at Albany, State University of New York, Albany, New York

\author{
LANCE F. BOSART \\ Department of Atmospheric and Environmental Sciences, University at Albany, \\ State University of New York, Albany, New York
}

(Manuscript received 2 May 2019, in final form 13 September 2019)

\begin{abstract}
The Great Plains (GP) low-level jet (GPLLJ) contributes to GP warm season water resources (precipitation), wind resources, and severe weather outbreaks. Past research has shown that synoptic and local mesoscale physical mechanisms (Holton and Blackadar mechanisms) are required to explain GPLLJ variability. Although soil moisture-PBL interactions are central to local mechanistic theories, the diurnal effect of regional soil moisture anomalies on GPLLJ speed, northward penetration, and propensity for severe weather is not well known. In this study, two 31-member WRF-ARW stochastic kinetic energy backscatter scheme ensembles simulate a typical warm season GPLLJ case under CONUS-wide wet and dry soil moisture scenarios. In the GP $\left(24^{\circ}-48^{\circ} \mathrm{N}, 103^{\circ}-90^{\circ} \mathrm{W}\right)$, ensemble mean differences in sensible heating and PBL height of $25-150 \mathrm{~W} \mathrm{~m}^{-2}$ and $100-700 \mathrm{~m}$, respectively, at 2100 UTC (afternoon) culminate in GPLLJ 850-hPa wind speed differences of $1-4 \mathrm{~m} \mathrm{~s}^{-1} 12$ hours later (0900 UTC; early morning). Greater heat accumulation in the daytime PBL over dry soil impacts the east-west geopotential height gradient in the GP (synoptic conditions and Holton mechanism) resulting in a deeper thermal low in the northern GP, causing increases in the geostrophic wind. Enhanced daytime turbulent mixing over dry soil impacts the PBL structure (Blackadar mechanism), leading to increased ageostrophic wind. Overnight geostrophic and ageostrophic winds constructively interact, leading to a faster nocturnal GPLLJ over dry soil. Ensemble differences in CIN $\left(\sim 50-150 \mathrm{~J} \mathrm{~kg}^{-1}\right)$ and CAPE $\left(\sim 500-1000 \mathrm{~J} \mathrm{~kg}^{-1}\right)$ have implications for severe weather predictability.
\end{abstract}

\footnotetext{
Corresponding author: Matthew A. Campbell, mcampbell6@ albany.edu
}

\section{Introduction}

The U.S. Great Plains (GP) is currently well studied in the hydrological and meteorological communities for two main reasons: 1 ) it serves as the corridor of a prominent low-level jet (LLJ) and 2) it is a "hot spot" for modeled land-atmospheric coupling strength. 
Both research themes are socially motivated by the need to better understand and predict precipitation in a region that is highly susceptible to seasonal droughts, such as the 2012 "flash drought" (e.g., Hoerling et al. 2014), and prolonged multiyear droughts, such as the Dust Bowl of the 1930s (NCEI 2019). The GP's $\$ 92$ billion per year crop and livestock industry critically depends on GP low-level jet (GPLLJ)-related precipitation (Basara et al. 2013; Melillo et al. 2014). Furthermore, GPLLJ-related wind events in Texas, Oklahoma, Kansas, and Nebraska collectively support up to $45 \%$ of the U.S. installed wind energy generation capacity (AWEA 2018).

First objectively defined by Bonner (1968), the GPLLJ is characterized by a diurnally oscillating, lowlevel wind maximum between 0 and $3 \mathrm{~km}$ above ground level with decreasing winds above (e.g., Helfand and Schubert 1995; Mitchell et al. 1995; Whiteman et al. 1997) and below (e.g., Walters and Winkler 2001) the nose of the LLJ. The frequency of GPLLJ occurrence tends to peak in the warm season due to long-term seasonal heating of the GP's gently westward-upwardsloping terrain that leads to the development of thermal wind forcing conducive to GPLLJ development (e.g., Parish 2017). Under synoptically quiescent periods (i.e., lack of quasigeostrophic forcing), the GPLLJ tends to develop around sunset, veer overnight, and maximize in intensity between 0600 and 0900 UTC (early morning) (e.g., Song et al. 2005; Berg et al. 2015). The GPLLJ is the primary conveyor of atmospheric moisture from the Gulf of Mexico northward, from Texas to southern Manitoba and Saskatchewan, along an axis which varies between approximately $103^{\circ}$ and $90^{\circ} \mathrm{W}$. GP warm season precipitation (e.g., Means 1954; Dirmeyer and Brubaker 1999), severe weather, tornado outbreaks (e.g., Muñoz and Enfield 2011), and mesoscale convective systems (MCSs) are largely driven, sustained, and modulated by the GPLLJ (e.g., Maddox 1983; Cotton et al. 1989; Coniglio et al. 2010) through moisture convergence (e.g., Helfand and Schubert 1995; Higgins et al. 1997; Wang and Chen 2009) and vertical wind shear at the jet's northern exit region (e.g., French and Parker 2010).

The GP land-atmosphere coupling "hotspot" terminology was borne out of the GEWEX Global Land Atmospheric Coupling Experiment (Koster et al. 2004; Guo et al. 2006; Koster et al. 2006), which demonstrated, using an ensemble of coarse resolution global circulation models, that realistic soil moisture can improve predictability of GP 2-m temperature and precipitation on subseasonal time scales. Later, using atmospheric reanalysis datasets, the strength of the hotspot was shown to be largely dependent upon moisture convergence associated with the GPLLJ and soil moisture availability (Song et al. 2016). In the context of GPLLJ-forced subseasonal to seasonal precipitation variability, which cannot be fully explained by internal atmospheric variability (e.g., Yu et al. 2017) or sea surface temperature forced variability (e.g., Schubert et al. 2004; Song et al. 2005; Yang et al. 2007; Kam et al. 2014; Krishnamurthy et al. 2015; Yu et al. 2017), an important outstanding question is: How sensitive is the GPLLJ to regional soil moisture anomalies and how may this sensitivity be explained dynamically?

Uccellini (1980) laid the framework for differentiating GPLLJs according to the relative strength of their largescale synoptic forcing (e.g., ridge or trough-ridge systems) as compared to local land-atmospheric forcing. GPLLJ's may be either 1) coupled to the upper-level jet stream via a thermally indirect circulation associated with the upper-level jet exit region (Uccellini and Johnson 1979) or 2) uncoupled from the upper-level jet stream and dominated by local land and planetary boundary layer (PBL) processes. According to Uccellini (1980), uncoupled GPLLJs tend to exhibit a clear diurnal cycle and occur when there is a large ridge over the central United States with weak flow aloft over the southern GP. Uncoupled GPLLJ winds strengthen and veer overnight, peaking in intensity in the early morning hours above the nocturnal PBL and within the residual mixed layer. In contrast, coupled GPLLJs are influenced by upper-level jet streaks and have synoptic support. Coupled GPLLJs and their supporting upper-level jets occur when there is an upper-level trough over the western United States that is propagating toward the GP and jet streaks are ejecting into the central United States from the southwest. Coupled GPLLJs may not always exhibit as clear a diurnal signal as uncoupled jets because the physical mechanisms driving coupled GPLLJs are only partially explained by diurnally driven local terrain and PBL processes. In reality, each GPLLJ will have a unique mix of both local and synoptic support.

The GP local land conditions favor two primary mechanisms for uncoupled, or synoptically quiescent GPLLJs: 1) inertial oscillations in the PBL due to reductions in nocturnal friction of the low-level flow (Blackadar 1957, hereafter the Blackadar mechanism) and 2) diurnal fluctuations in the lower-tropospheric east-west thermal and geopotential height profiles across sloping terrain (Holton 1967, hereafter the Holton mechanism). Idealized numerical modeling efforts have expanded our understanding of the Blackadar and Holton mechanisms in the ways that these two mechanisms force the GPLLJ, especially during periods of synoptic quiescence (Shapiro and Fedorovich 2010; Du and Rotunno 2014; Shapiro et al. 2016; 
Fedorovich et al. 2017). Regardless of the mechanism or combination of mechanisms that are active for a given GPLLJ event, it is hypothesized that perturbations to the soil moisture state may lead to modulation, suppression, or enhancement of the GPLLJ through PBL height $(\mathrm{PBLH})$ adjustments via modified turbulent eddy fluxes (e.g., Ek and Mahrt 1994; Ek and Holtslag 2004; Santanello et al. 2018) and modifications to the east-west temperature and geopotential height gradients across the GP (McCorcle 1988; Fast and McCorcle 1990; Zhong et al. 1996).

It is also important to acknowledge the theorized impacts of terrain-blocked flow on the GPLLJ as discussed by Wexler (1961). Wexler largely attributed GPLLJ formation to the northward turning of the trade winds due to mechanical blocking by the North American Cordillera. While it is still widely accepted that the climatological placement of the Bermuda high and southerly background flow is important for GPLLJ formation, studies (e.g., Parish and Oolman 2010) have highlighted inconsistencies between the GPLLJ and physical processes associated with other LLJs that are purely resultant from terrain-blocked flow (Bell and Bosart 1988). The current understanding is that the GPLLJ and terrain are physically linked through heating of the sloping terrain in the GP that may be impacted by soil moisture, not through mechanical blocking of the trade winds and formation of a barrier jet (i.e., Parish 2017).

In this study, an ensemble modeling approach using the Advanced Research Weather Research and Forecasting (WRF-ARW, hereafter WRF) Model, version 3.9.1.1 (Skamarock et al. 2008), is employed to assess the impact of regional soil moisture availability on the GPLLJ and associated weather. Specifically, the diurnal impact of extreme wet and dry soil moisture states on an uncoupled GPLLJ is investigated. It will be shown that dry soil results in a stronger GPLLJ, by $1-4 \mathrm{~m} \mathrm{~s}^{-1}$ at $850 \mathrm{hPa}$, compared to wet soil. Ultimately, the modeled differences between wet and dry soil ensemble means are due to increased surface sensible heating over dry soil compared to wet soil. The dynamical impacts of surface sensible heat fluxes are then discussed in terms of the two primary GPLLJ formation mechanisms (Blackadar and Holton mechanisms) and synoptic conditions.

The remainder of the paper is organized as follows. Section 2 describes the criteria used to select the case study, the WRF Model configuration, the experimental design, and significance testing. Section 3 presents a synoptic overview of the case selected and the effect of soil moisture prescription on the GPLLJ, sensible weather, severe weather parameters, and the geostrophic/ageostrophic components of the wind. Section 4 discusses the dynamical drivers of the GPLLJ and concludes the manuscript.

\section{Data and methods}

\section{a. Case selection}

To investigate the diurnal impacts of soil moisture on a typical summertime GPLLJ, the criteria set by Uccellini (1980) to describe a "classic" uncoupled GPLLJ is employed to select the synoptic environment for the case used in this experiment. A LLJ criteria, similar to the one first introduced by Bonner (1968), and later modified by Walters and Winkler (2001), to describe the vertical wind shear profile of a LLJ, is also used. To be considered a LLJ, the wind speed must increase with height above the surface and ultimately peak in the lower troposphere before decreasing with height above the level of maximum winds. More specifically, the 850 -hPa wind speed, which is commonly used to analyze the GPLLJ, must be at least $4 \mathrm{~m} \mathrm{~s}^{-1}$ greater than the near-surface and $700-\mathrm{hPa}$ wind speed. The use of $4 \mathrm{~ms}^{-1}$ of vertical wind shear above and below the GPLLJ is consistent with the vertical wind shear criteria used by Walters and Winkler (2001). Using ERA-Interim reanalysis (Dee et al. 2011) and taking into account the aforementioned LLJ criteria, the uncoupled GPLLJ, which spans the entire GP, on the morning of 21 July 2017 (Fig. 1) is selected for further analysis.

\section{b. The model}

For this experiment, WRF is implemented with a horizontal resolution of $27 \mathrm{~km}$, which is suitable for GPLLJ studies (e.g., Helfand and Schubert 1995; Zhong et al. 1996; Doubler et al. 2015), and 50 sigma coordinate vertical levels between the surface and $50 \mathrm{hPa}$. A large domain is modeled to ensure that GPLLJ processes are contained well within the domain boundaries (Fig. 2). For example, the domain includes dynamically important regions for GPLLJ variability, such as the Gulf of Mexico, the western North Atlantic, and the Rocky Mountains. Instead of running various physics parameterizations in order to generate an ensemble, WRF is run with a single physics configuration (see Table 1) and an ensemble is constructed using the stochastic kinetic energy backscatter scheme (SKEBS; Shutts 2005) described in section $2 \mathrm{~d}$. The SKEBS approach constrains the degrees of freedom in the experiment and supports statistical significance testing.

\section{c. Experimental design}

The initial and boundary conditions for all variables, except soil moisture, for WRF are provided by the 

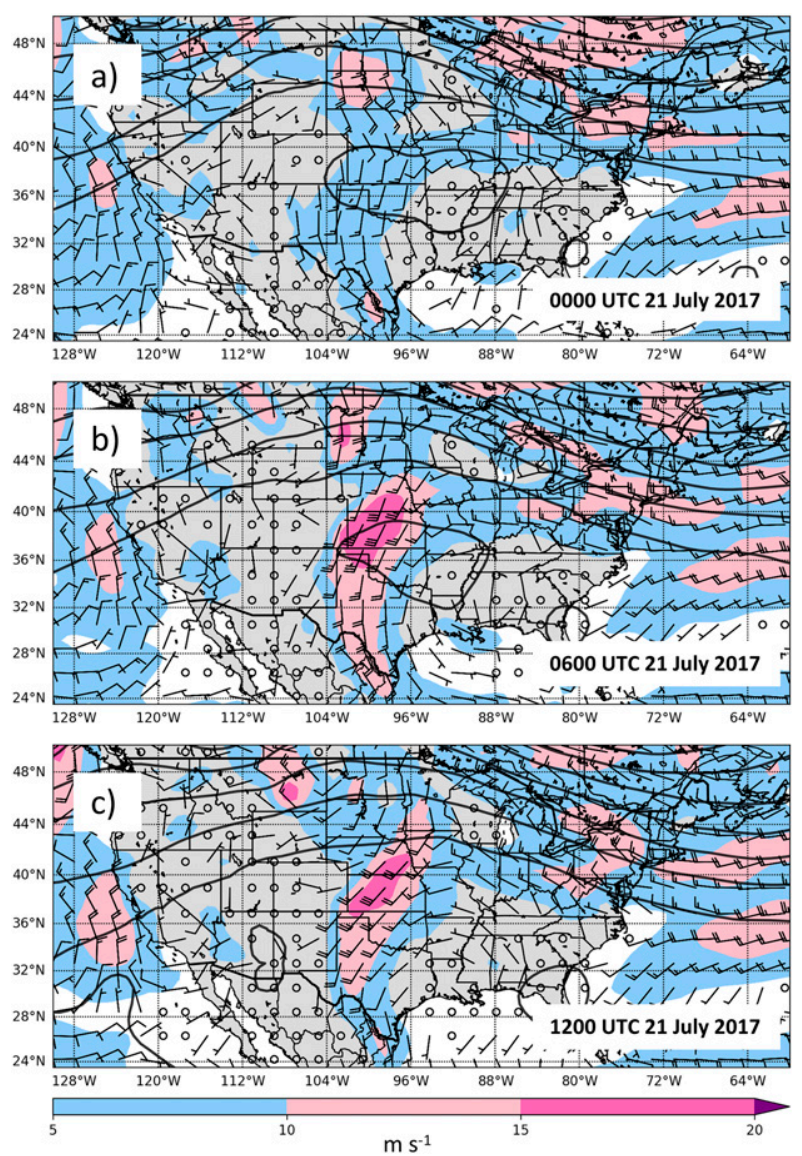

FIG. 1. ERA-Interim reanalysis derived synoptic environment at (a) 0000, (b) 0600, and (c) 1200 UTC 21 Jul 2017. 850-hPa wind speed (shaded; $\mathrm{m} \mathrm{s}^{-1}$ ), wind vectors (barbs; half barb is $2.5 \mathrm{~m} \mathrm{~s}^{-1}$, full barb is $5 \mathrm{~m} \mathrm{~s}^{-1}$, and flag is $25 \mathrm{~m} \mathrm{~s}^{-1}$ ), and 500-hPa geopotential height (black contours; every 5 dam) are shown. Land is shaded in gray and oceans are white.

ERA-Interim reanalysis dataset. The simulations are initialized at 0000 UTC 20 July 2017, which is $24 \mathrm{~h}$ prior to the GPLLJ of interest, and end at 1800 UTC 21 July 2017, which is after the cessation of the GPLLJ of interest. Atmospheric boundary conditions are updated at the temporal resolution of ERA-Interim, which is every $6 \mathrm{~h}$.

To test GPLLJ sensitivity to soil moisture, two contrasting soil moisture scenarios are prescribed in all four soil layers upon WRF initialization. The soil moisture prescriptions are generated using Noah Version 3.6 land surface model (Noah LSM) matched identically to its configuration in WRF. The Noah LSM is run from 1981 to 2016, with one year of spinup, using the NASA Land Information System (LIS; Kumar et al. 2006; Peters-Lidard et al. 2007) software framework in order to create a daily, model-based warm season (MaySeptember) climatology of soil moisture at each grid

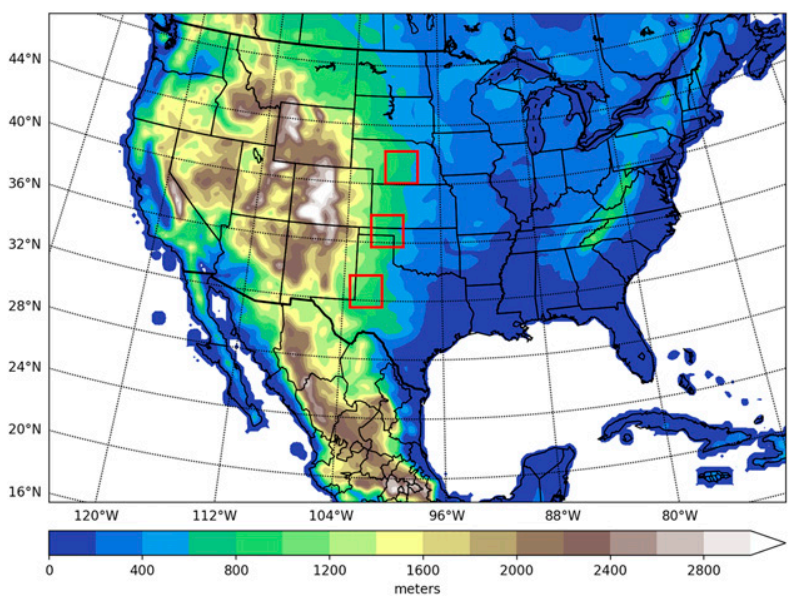

FIG. 2. Topography over the WRF Model domain, based on GTOPO30 (Gesch et al. 1999). Horizontal grid size is $27 \mathrm{~km}$ and 50 vertical levels are used between the surface and $50 \mathrm{hPa}$. Red boxes outline the northern, central, and southern GP analysis regions.

point over the domain. The LIS-Noah simulation uses the same model physics, soil and surface vegetation parameterizations, and grid mesh as the coupled WRF Model. The hourly meteorological forcing for the LIS-Noah simulation comes from the ModernEra Retrospective Analysis for Research and Applications, version 2 (MERRA-2; Gelaro et al. 2017; Reichle et al. 2017) and includes bias-corrected precipitation. For the WRF simulations, the 95th percentile and 5th percentiles of 1982-2016 warm-season daily volumetric soil moisture content at each grid point and for each of Noah LSM's four soil layers are prescribed at initialization. The 95th percentile represents wet soil conditions (Fig. 3a) at each grid point and the 5th percentile represents dry soil conditions (Fig. 3b) at each grid point. The differences between the wet and dry soil moisture prescriptions in each of the four soil layers is plotted in Figs. 3c-f. The top layer $(0-10 \mathrm{~cm}$ layer) soil moisture differences in the GP are approximately of $0.05-0.15 \mathrm{~m}^{3} \mathrm{~m}^{-3}$. The 95 th and 5 th percentiles of climatological warm season soil moisture are used in order to maximize the soil moisture-GPLLJ sensitivity signal. If 95 th-5th percentile differences in regional soil moisture cannot dynamically generate a GPLLJ response, it is hypothesized that smaller differences cannot either.

\section{d. Significance testing}

Quantifying model uncertainty with a full WRF multiphysics ensemble (e.g., Mooney et al. 2017) was deemed beyond the scope of this study. Instead, a SKEBS (Berner et al. 2011, 2015) ensemble-based approach is used to test for statistical significance. 
TABLE. 1. Parameterizations selected for the WRF simulations in this study.

\begin{tabular}{lll}
\hline \multicolumn{1}{c}{$\begin{array}{c}\text { WRF } \\
\text { parameterizations }\end{array}$} & \multicolumn{1}{c}{ Reference } & \multicolumn{1}{c}{ Selection } \\
\hline $\begin{array}{l}\text { Microphysics } \\
\text { Cumulus }\end{array}$ & Thompson et al. (2008) & Thompson \\
Boundary layer & Kain (2004) & Kain-Fritsch \\
Land surface & Ek et al. (2003) & YSU \\
Surface layer & Jiménez et al. (2012) & Moah v3.6 \\
& & Monin-Obukhov \\
& & similarity \\
Longwave radiation & Iacono et al. (2008) & RRTMG \\
Shortwave radiation & Iacono et al. (2008) & RRTMG \\
\hline
\end{tabular}

Prior studies have demonstrated SKEBS can account for physical uncertainty associated with subgrid-scale turbulence (e.g., Berner et al. 2011, 2015; Judt et al. 2016). Following the most common SKEBS approach, suggested default white noise perturbations are applied to the potential temperature and rotational wind component fields continuously, at every model time step and only within the model domain interior. As described in the WRF user manual (NCAR 2017), these default values are tuned for the synoptic-scale perturbations in middle latitudes, consistent with our use case. The lateral boundary conditions are not perturbed as synoptic uncertainty associated with the ERA-Interim reanalysis dataset is not the focus of this study.

One ensemble group consists of members initialized with wet soil moisture conditions and the other ensemble group consists of members initialized with dry soil moisture conditions. As a reminder, soil moisture prescription is performed at each grid point and for each of the four soil layers. Each ensemble group contains 31 total members: 1 control run without SKEBS perturbations and 30 members generated by setting the random number seed in SKEBS from 1 to 30. A difference of means $t$ test is conducted for each grid point in order to test if the two ensemble groups are statistically different at the $95 \%$ confidence level (i.e., $p$ value less than or equal to 0.05 ) for selected meteorological fields. Using SKEBS to generate ensembles and testing for statistical significance should help to increase the probability that apparent differences between the wet and dry ensembles are the result of physically relevant processes and are not due to random chance or model uncertainty.

The wet and dry soil moisture ensemble mean fields are compared and contrasted within the GP from approximately $24^{\circ}-48^{\circ} \mathrm{N}$ and $103^{\circ}-90^{\circ} \mathrm{W}$. The primary time selected for analysis is 0900 UTC 21 July 2017 (simulation hour 33) because GPLLJ wind speed differences between ensembles are maximized at this time. Additional analyses are provided for the northern, central, and southern GP subregions outlined in Fig. 2. These regional analyses use area-averaged fields.

\section{Results}

\section{a. Synoptic setup}

The GPLLJ of 21 July 2017 exhibits defining characteristics of a "classic" uncoupled GPLLJ (Uccellini 1980). According to the ERA-Interim reanalysis, a large upper-level ridge at $500 \mathrm{hPa}$ was present over the central United States at 0600 UTC 21 July 2017 (Fig. 1b).

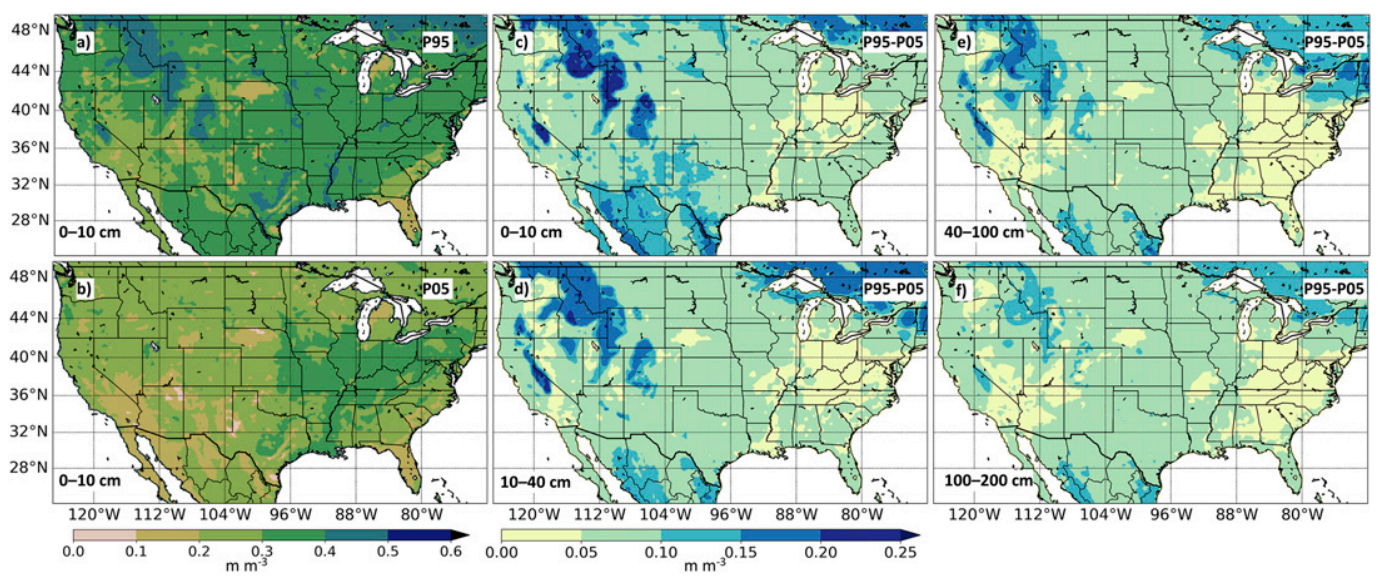

FIG. 3. (a) 95th and (b) 5th percentile Noah v3.6 daily warm season (May-September) 0-10 cm (top layer) volumetric soil moisture $\left(\mathrm{m}^{3} \mathrm{~m}^{-3}\right)$ and (c) their difference (95th-minus-5th percentile). Fields are calculated from a 34-yr (1982-2016) NASA-LIS offline simulation with identical surface model physics, (soil and vegetative) parameters, and grid mesh as the coupled WRF configuration. (d) As in (c), but for 10-40 cm layer. (e) As in (c), but for 40-100 cm layer. (f) As in (c), but for 100-200 cm layer. 
The GPLLJ at $850 \mathrm{hPa}$ was located directly under the upper-level ridge axis. There was weak flow aloft (not shown), especially over the central and southern GP, indicative of a lack of upper-level jet stream support for GPLLJ formation. Clear sky conditions were present and warm conditions persisted over much of the region. Similar analysis at 0000 (Fig. 1a) and 1200 UTC (Fig. 1c) 21 July 2017 reveal a nocturnally oscillating GPLLJ at $850 \mathrm{hPa}$ with veering winds overnight and the GPLLJ first appearing after 0000 UTC. Furthermore, as shown later in the results section, the WRF simulations conducted for this study similarly reproduce the GPLLJ as it appears in the ERA-Interim reanalysis and confirm the presence of defining characteristics used to classify an uncoupled GPLLJ.

\section{b. GPLLJ 850-hPa total winds}

At 2100 UTC 20 July 2017 (simulation hour 21), WRF simulations depict a broad area of $5-15 \mathrm{~m} \mathrm{~s}^{-1}$ southerly winds over the central GP at $850 \mathrm{hPa}$ (Figs. 4a,b). Concurrently, an $850-\mathrm{hPa}$ geopotential height field analysis reveals a ridge centered over the southern Mississippi River valley and a trough located over the northern GP resulting in south-southwesterly geostrophic flow over the central GP. The total winds, which are the sum of the geostrophic and ageostrophic winds, are southerly over the GP and there is no evidence of a GPLLJ at $850 \mathrm{hPa}$. The vertical wind shear profile over the GP does not meet the shear requirement for a GPLLJ (not shown) and the boundary layer is well mixed. Furthermore, the differences between the wet and dry ensembles' mean $850-\mathrm{hPa}$ wind speed are small and generally less than $1 \mathrm{~m} \mathrm{~s}^{-1}$ (Figs. 4c and 6).

At 0000 UTC 21 July 2017, there is no GPLLJ and 850-hPa winds are between 5 and $15 \mathrm{~m} \mathrm{~s}^{-1}$ (Figs. 4d,e). However, after sunset, between 0000 and 0300 UTC, the GPLLJ forms as the 850 -hPa wind increases by approximately $5 \mathrm{~m} \mathrm{~s}^{-1}$ and the required GPLLJ vertical wind shear profile is achieved as the boundary layer decouples. By 0300 UTC a somewhat discontinuous southerly GPLLJ is analyzed over the GP (Figs. 4g,h) with $850-\mathrm{hPa}$ wind speed exceeding $15 \mathrm{~m} \mathrm{~s}^{-1}$ in two areas. A southernmost wind maximum is located in southwestern Texas-northeastern Mexico and a northernmost wind maximum is located at the KansasNebraska border. During the early evening hours of 0000 and 0300 UTC, differences between wet and dry ensemble 850-hPa GPLLJ winds (Figs. 4f,i) remain negligible (less than $1 \mathrm{~m} \mathrm{~s}^{-1}$ ) and the wind veers over time (characteristic of an inertial oscillation).

At 0600 and 0900 UTC, a well-organized, continuous, southwesterly GPLLJ at $850 \mathrm{hPa}$ extends from Texas to Nebraska (Figs. 5a,b,d,e) with the core of the jet located over the central GP. GPLLJ winds reach peak intensity at 0600 UTC when the average GPLLJ wind speed is maximized over the central GP. Specifically, the wind speed in the core of the GPLLJ over dry soil exceeds $20 \mathrm{~m} \mathrm{~s}^{-1}$ over Kansas and Nebraska at this time. At 0900 UTC (simulation hour 33) the GPLLJ becomes better organized, or more spatially continuous, as demonstrated by closed 850 -hPa wind speed contours of $15 \mathrm{~m} \mathrm{~s}^{-1}$ spanning the entire GP. Analysis at $850 \mathrm{hPa}$ from earlier timesteps reveal gaps in the GPLLJ's $15 \mathrm{~m} \mathrm{~s}^{-1}$ contours over Texas.

In these early morning hours of 0600 and 0900 UTC, winds veered from 0300 UTC (indicative of an inertial oscillation) and both wet and dry soil moisture ensemble means place the core of the GPLLJ in the same location evolving similarly over time. The 850-hPa wind direction between ensembles is also comparable, but wind speed differences greater than $1 \mathrm{~m} \mathrm{~s}^{-1}$ are apparent especially in the southern and northern GP (Figs. 5c,f and 6). At 0900 UTC, the wet ensemble mean 850-hPa wind speed is approximately $1-4 \mathrm{~m} \mathrm{~s}^{-1}$ slower relative to the dry ensemble mean (Fig. 5f). The largest wind speed differences occur near the entrance and exit regions of the GPLLJ. The GPLLJ location does not appear to be shifted because the core of the GPLLJ is in the same location in both ensemble mean fields. GPLLJ 850-hPa wind speed differences between the ensembles are also statistically significant at 0600 and 1200 UTC (Figs. 5c,i), ranging from 1 to $3 \mathrm{~m} \mathrm{~s}^{-1}$. Histograms of ensemble member $850-\mathrm{hPa}$ wind speed from 0600 to 1200 UTC within the regional subdomains of Fig. 2 reflect a shift of the entire wind speed distribution occurs between ensembles (not shown). Variance and the overall shape of the histograms remain comparable. At 1500 UTC (post sunrise), after the PBL has already grown considerably, ensemble mean $850 \mathrm{hPa}$ wind speed differences diminish to less than $1 \mathrm{~m} \mathrm{~s}^{-1}$ (not shown). It will be shown in section $3 \mathrm{f}$ that the $850-\mathrm{hPa}$ wind evolution and wind speed differences are due to individual contributions of the geostrophic and ageostrophic wind.

\section{c. Surface fluxes and the $P B L$}

Soil moisture driven differences in surface latent heat flux, sensible heat flux, and PBL structure (e.g., Fischer et al. 2007; Case et al. 2011) are apparent. At 2100 UTC 20 July 2017 (around peak heating), there is more surface latent heat flux and less surface sensible heat flux over wet soil compared to dry soil over almost all of the domain (Figs. 7a-f). Differences in sensible and latent heat flux generally range from 25 to $100 \mathrm{~W} \mathrm{~m}^{-2}$, although isolated areas in the southern GP experience differences exceeding $100 \mathrm{~W} \mathrm{~m}^{-2}$. Over wet soil, a greater fraction of total energy goes toward latent 


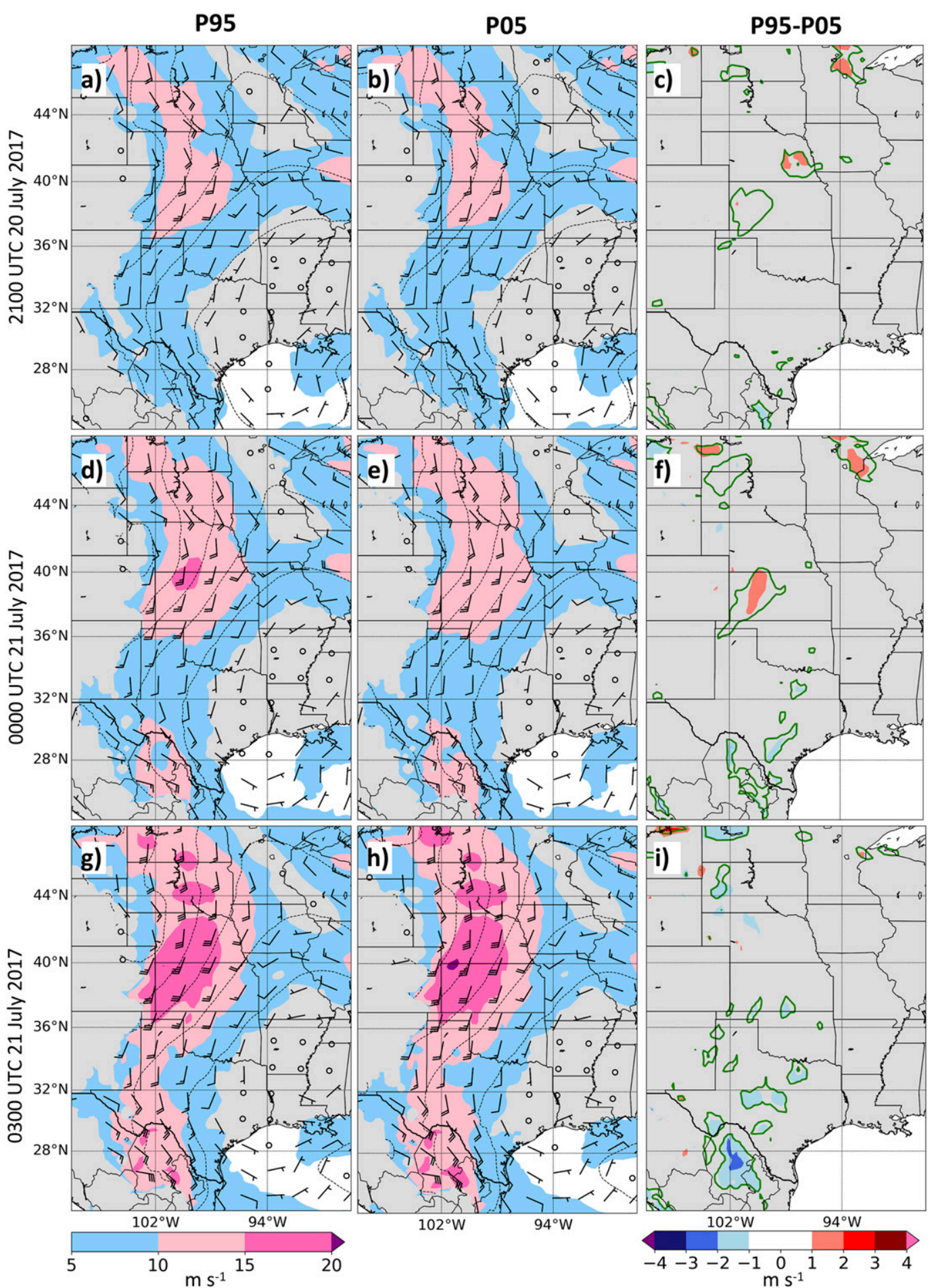

FIG. 4. (a) WRF-derived mean 850 -hPa wind speed (shaded; $\mathrm{m} \mathrm{s}^{-1}$ ), wind vectors (barbs; $\mathrm{m} \mathrm{s}^{-1}$ ), and geopotential height (dashed contours; every 2 dam) for the wet ensemble at 2100 UTC 20 Jul 2017. (b) As in (a), but for dry ensemble. (c) Difference between wet and dry ensemble mean 850-hPa wind speed (shaded; $\mathrm{m} \mathrm{s}^{-1}$ ). Solid green outline denotes regions where difference of means $t$ test for ensemble $850-\mathrm{hPa}$ wind speed is statistically significant $(p \leq 0.05)$. (d) As in (a), but at 0000 UTC 21 Jul 2017. (e) As in (b), but at 0000 UTC 21 Jul 2017. (f) As in (c), but at 0000 UTC 21 Jul 2017. (g) As in (a), but at 0300 UTC 21 Jul 2017. (h) As in (b), but at 0300 UTC 21 Jul 2017. (i) As in (c), but at 0300 UTC $21 \mathrm{Jul} 2017$. Land is shaded in gray and oceans are white. Values from -1.0 to $1.0 \mathrm{~m} \mathrm{~s}^{-1}$ (small differences) in the difference plots are not shaded. 


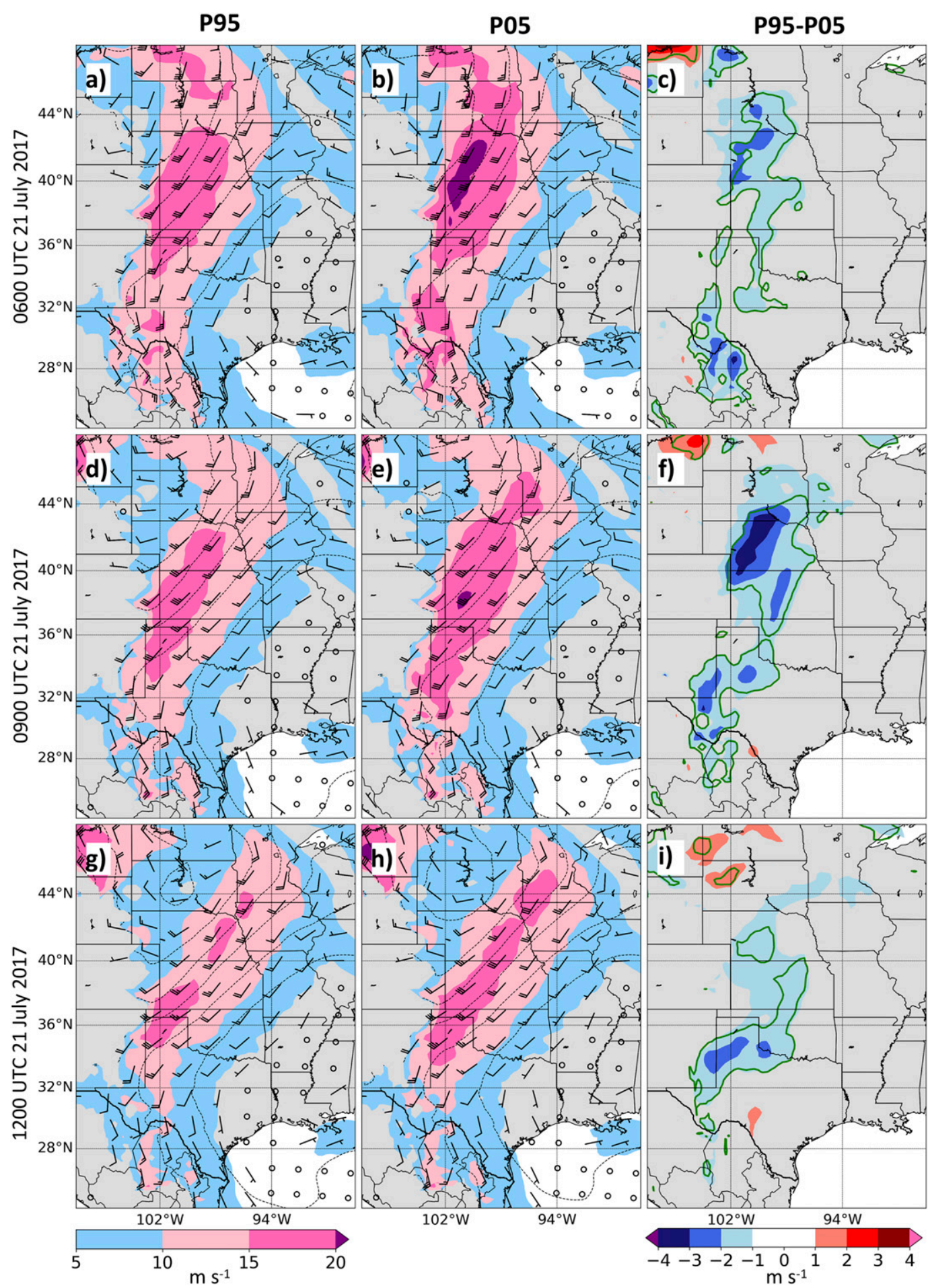

FIG. 5. (a) WRF-derived mean $850-\mathrm{hPa}$ wind speed (shaded; $\mathrm{m} \mathrm{s}^{-1}$ ), wind vectors (barbs; $\mathrm{m} \mathrm{s}^{-1}$ ), and geopotential height (dashed contours; every 2 dam) for the wet ensemble at 0600 UTC 21 Jul 2017. (b) As in (a), but for dry ensemble. (c) Difference between wet and dry ensemble mean 850-hPa wind speed (shaded; $\mathrm{m} \mathrm{s}^{-1}$ ). Solid green outline denotes regions where difference of means $t$ test for ensemble 850-hPa wind speed is statistically significant ( $p \leq 0.05)$. (d) As in (a), but at 0900 UTC 21 Jul 2017. (e) As in (b), but at 0900 UTC 21 Jul 2017. (f) As in (c), but at 0900 UTC 21 Jul 2017. (g) As in (a), but at 1200 UTC 21 Jul 2017. (h) As in (b), but at 1200 UTC 21 Jul 2017. (i) As in (c), but at 1200 UTC 21 Jul 2017. Land is shaded in gray and oceans are white. Values from -1.0 to $1.0 \mathrm{~m} \mathrm{~s}^{-1}$ (small differences) in the difference plots are not shaded. 


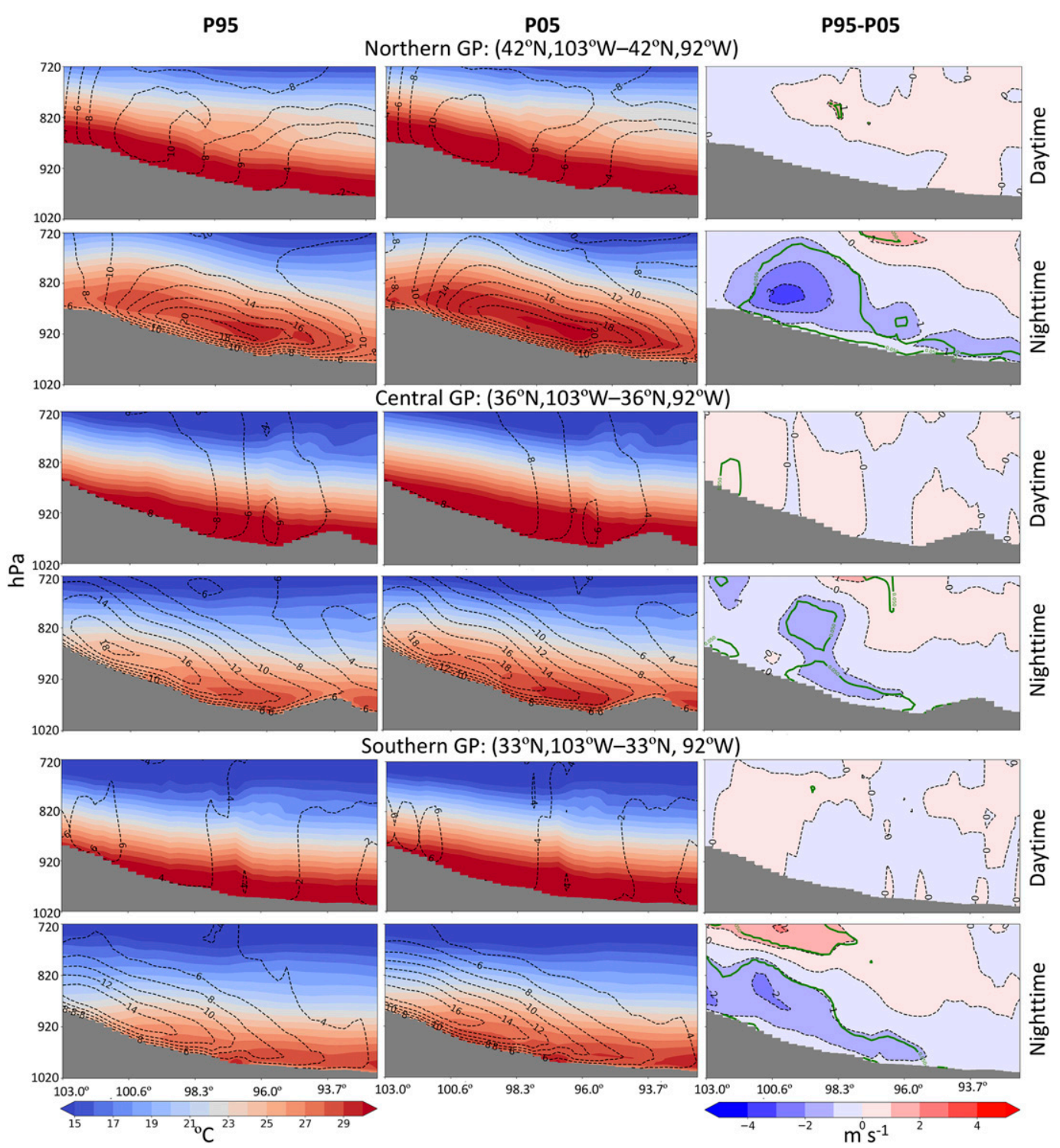

FIG. 6. (left),(center) Vertical cross sections of temperature (shaded; ${ }^{\circ} \mathrm{C}$ ), wind speed (dashed lines; $\mathrm{m} \mathrm{s}^{-1}$ ), and terrain (gray fill) through the northern, central, and southern GP at 2100 UTC 20 Jul 2017 (afternoon) for wet (P95) and dry (P05) ensembles. (right) Vertical cross sections of wet minus dry (P95-P05) ensemble wind speed differences (dashed; shaded; $\mathrm{m} \mathrm{s}^{-1}$ ), and terrain (gray fill); solid green outline denotes areas where difference of means $t$ test for ensemble wind speed differences are statistically significant $(p \leq 0.05)$. The vertical axis is pressure $(\mathrm{hPa})$ and the horizontal axis is longitude (west). Nighttime is 0900 UTC 21 Jul 2017.

heating than in the dry soil cases. At the same time (i.e., 2100 UTC), PBL height (PBLH) is 100-700 m higher over dry soil compared to wet soil (Figs. $7 \mathrm{~g}-\mathrm{i}$ ). Deeper PBL growth over dry soil is driven by increased sensible heating compared to wet soil. Interensemble differences between in the PBLH and surface heat flux fields are largest during the daytime hours. Overnight, the differences in these fields are negligible (not shown) as the PBL collapses and surface heat fluxes approach zero in both simulations in the absence of solar heating. The impacts of the daytime surface heat fluxes ultimately manifest themselves as dynamical drivers of the nocturnal GPLLJ wind and sensible weather differences between ensembles.

\section{d. Sensible weather}

Surface temperature and dewpoint temperature fields exhibit robust differences between the wet and dry soil moisture ensembles over broad regions of the domain at 0900 UTC 21 July 2017 (Figs. 8a-f) due to daytime 

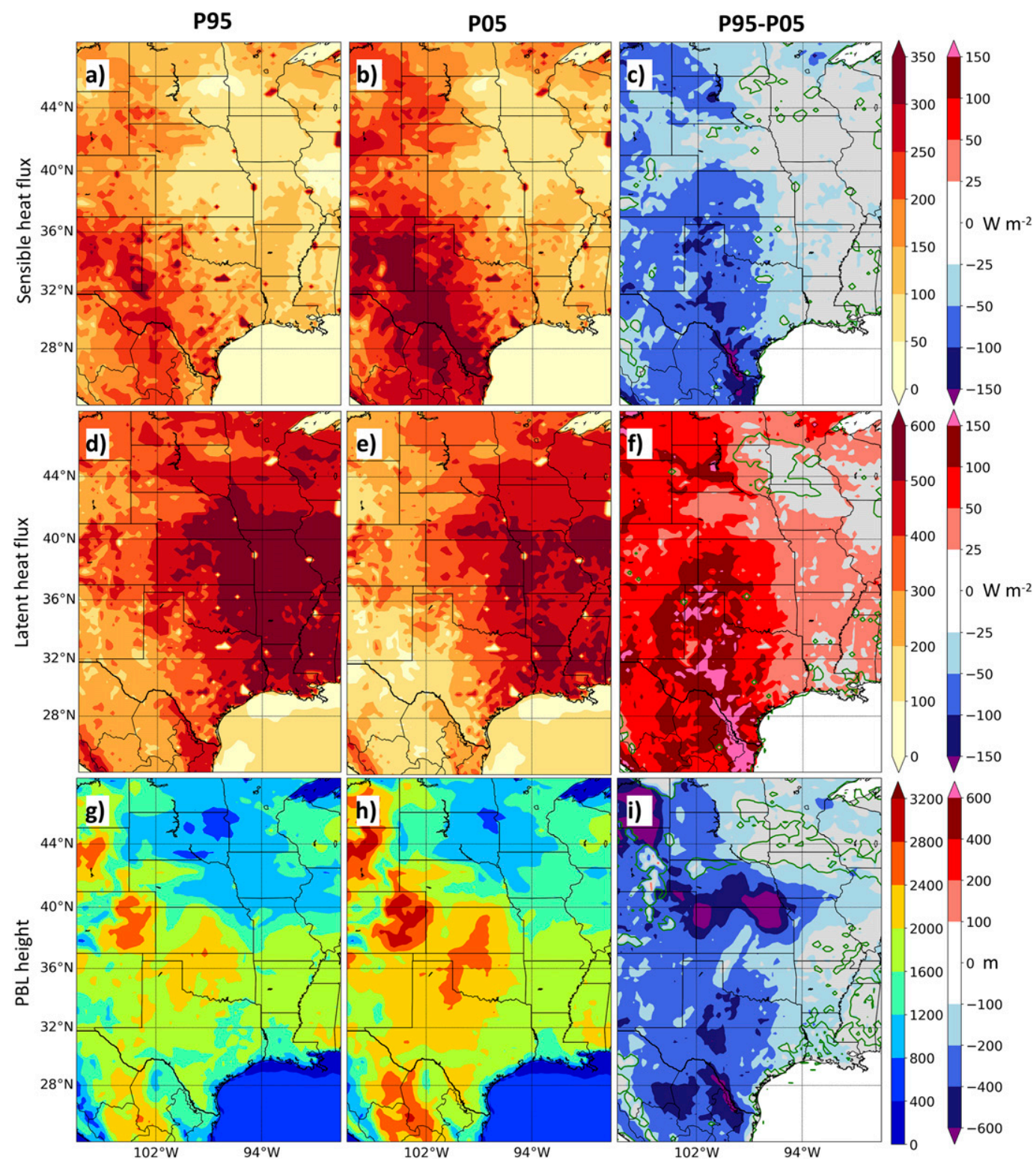

FIG. 7. (a) WRF-derived mean surface sensible heat flux (shaded; $\mathrm{W} \mathrm{m}^{-2}$ ) for the wet ensemble at 2100 UTC 20 Jul 2017. (b) As in (a), but for dry ensemble. (c) Difference between wet and dry ensemble mean sensible heat flux (shaded; $\mathrm{W} \mathrm{m}^{-2}$ ). Solid green outline denotes regions where difference of means $t$ test for ensemble sensible heat flux is statistically significant ( $p \leq 0.05$ ). (d) WRF-derived mean surface latent heat flux (shaded; $\mathrm{W} \mathrm{m}^{-2}$ ) for the wet ensemble at 2100 UTC $20 \mathrm{Jul}$ 2017. (e) As in (d), but for dry ensemble. (f) As in (c), but for latent heat flux (W m ${ }^{-2}$ ). (g) Mean planetary boundary layer height (PBLH) (shaded; m) for the wet ensemble at 2100 UTC 20 Jul 2017. (h) As in (g), but for dry ensemble. (i) As in (c), but for PBLH (m). Land is shaded in gray and oceans are white. Values from -25.0 to $25.0 \mathrm{~W} \mathrm{~m}^{-2}$ (sensible heat flux), -25.0 to $25.0 \mathrm{~W} \mathrm{~m}^{-2}$ (latent heat flux), and -100.0 to $100.0 \mathrm{~m}$ (PBLH) (small differences) in the difference plots are not shaded.

differences in heat flux partitions. The wet ensemble mean $2 \mathrm{~m}$ temperature is $0.5^{\circ}-2.0^{\circ} \mathrm{C}$ cooler over the GP relative to the dry ensemble. Simultaneously, $2 \mathrm{~m}$ dewpoint temperature is $1^{\circ}-3^{\circ} \mathrm{C}$ higher over the GP in the wet ensemble mean field. The tendency for the wet ensemble to be more moist and cooler at the surface than the dry ensemble originates during the midmorning hours around 1500 UTC (not shown) and continues into the night. During the daytime the $2 \mathrm{~m}$ temperature over dry soil increases faster than over wet soil due to more sensible heat flux over dry soil. Concurrently, the $2 \mathrm{~m}$ dewpoint temperature over dry soil decreases, 

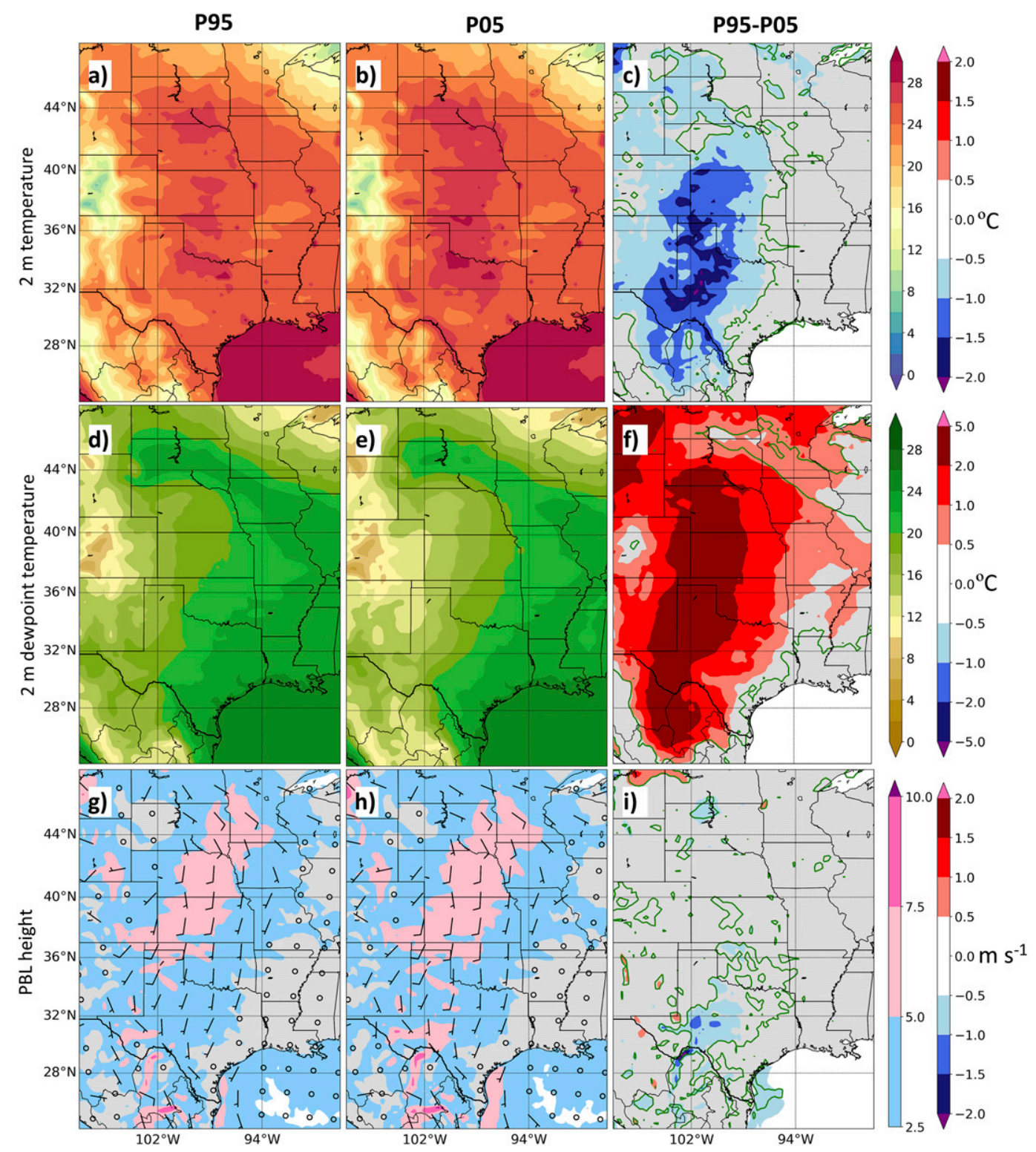

FIG. 8. (a) WRF-derived mean 2-m temperature (shaded; ${ }^{\circ} \mathrm{C}$ ) for the wet ensemble at $0900 \mathrm{UTC} 21 \mathrm{Jul} 2017$. (b) As in (a), but for dry ensemble. (c) Difference between wet and dry ensemble mean 2-m temperature (shaded; ${ }^{\circ} \mathrm{C}$ ). Solid green outline denotes regions where difference of means $t$ test for 2-m temperature is statistically significant $(p \leq 0.05)$. (d) WRF-derived mean 2-m dewpoint temperature (shaded; ${ }^{\circ} \mathrm{C}$ ) for the wet ensemble at 0900 UTC 21 Jul 2017. (e) As in (d), but for dry ensemble. (f) As in (c), but for 2-m dewpoint temperature $\left({ }^{\circ} \mathrm{C}\right)$. (g) Mean 10-m wind speed (shaded, $\mathrm{m} \mathrm{s}^{-1}$ ) and wind vectors (barbs; $\mathrm{m} \mathrm{s}^{-1}$ ) for the wet ensemble at 0900 UTC 21 Jul 2017. (h) As in (g), but for dry ensemble. (i) As in (c), but for 10-m wind speed ( $\mathrm{m} \mathrm{s}^{-1}$ ). Land is shaded in gray and oceans are white. Values from $-0.5^{\circ}$ to $0.5^{\circ} \mathrm{C}$ (2-m temperature), $-0.5^{\circ}$ to $0.5^{\circ} \mathrm{C}$ (2-m dewpoint temperature), and -0.5 to $0.5 \mathrm{~m} \mathrm{~s}^{-1}$ (10-m wind speed) (small differences) in the difference plots are not shaded.

or increases more slowly, than the $2 \mathrm{~m}$ dewpoint temperature over wet soil owing to the increase (decrease) in sensible (latent) heat flux owing from the lower soil water content. Increased entrainment of dry free-tropospheric air into the deeper daytime PBL over dry soil compared further contributes to lower $2 \mathrm{~m}$ dewpoint temperatures compared to wet soil.
Last, differences in $2 \mathrm{~m}$ temperature and dewpoint temperature between the two ensembles grow to a late-day maximum and decrease after sunset. This suggests that physical processes associated with the daytime insolation and vertical mixing are essential for developing the observed interensemble temperature and dewpoint temperature differences. 
Although the $2 \mathrm{~m}$ temperature and dewpoint temperature fields exhibit noticeable differences between ensembles, 10-m wind (near-surface wind), which is within the PBL during day and night, lacks sensitivity to soil moisture conditions. The interensemble $10 \mathrm{~m}$ wind speed differences are within $\pm 1 \mathrm{~m} \mathrm{~s}^{-1}$ at all times, including 0900 UTC 21 July 2017 (Figs. 8g-i) despite a slightly stronger pressure gradient over dry soil (not shown). There is a weak tendency for near-surface winds to be stronger over the GP during the daytime and slightly weaker at night over wet soil. However, the differences between ensemble means are small and the $t$-test results (not shown) do not exhibit any clear spatial patterns of statistically significant results. Surface friction effects within the PBL may help to explain the lack of near-surface wind sensitivity to soil moisture.

\section{e. Severe weather parameters}

Differences between the ensembles' sensible weather and GPLLJ winds lead to potentially important changes in parameters associated with severe weather occurrence. In this section, the thermodynamic profile is examined using the maximum convective available potential energy (CAPE) and maximum convective inhibition (CIN) at each grid point. Maximum CAPE and $\mathrm{CIN}$ are calculated on the parcel with the highest theta-e in the column within the first $3 \mathrm{~km}$ above ground. Parcel moisture and temperature attributes are then computed by averaging within $\pm 250 \mathrm{~m}$ of this layer. The kinematic environment, which is related to the GPLLJ, is examined using surface to $1-\mathrm{km}(0-1-\mathrm{km})$ wind shear. For this calculation, the vector difference between the $10-\mathrm{m}$ wind and the 1-km above ground level wind is calculated at each grid point and then the magnitude of the wind shear vector is computed.

At 0900 UTC 21 July 2017, more CAPE, which is not directly related to the GPLLJ, is modeled over wet soil as compared to dry soil (Figs. 9a-c). CAPE over wet soil is greater by $100-500 \mathrm{~J} \mathrm{~kg}^{-1}$ over most of the GP. Differences between wet and dry ensemble mean CAPE are largest near and just west of the GPLLJ exit region in South Dakota, ranging from 500 to $1500 \mathrm{~J} \mathrm{~kg}^{-1}$. CAPE increases in the GP over wet soil are largely attributable to increased lower-tropospheric moisture (Figs. 8d-f). However, low-level convergence near the northern end of the GPLLJ (not shown) might also play a role in enhancing the CAPE differences there. Differences in the spatial patterns of CIN (magnitude) between the wet and dry ensembles are less pronounced and the field is fairly noisy (Figs. 9d-f). Overall, differences between ensemble mean CAPE and CIN first develop and peak during the daytime as heating due to insolation warms Earth's surface and creates a surface-based mixed layer.
Daytime modifications are then carried into the nighttime hours.

Interensemble differences in $0-1-\mathrm{km}$ wind shear are noted from 0600 to 1200 UTC 21 July 2017 when GPLLJ wind speed differences are apparent (not shown). At 0900 UTC (Figs. $9 \mathrm{~g}-\mathrm{i}$ ), there is $1-3 \mathrm{~m} \mathrm{~s}^{-1}$ less $0-1-\mathrm{km}$ wind shear in the GP over wet soil compared to dry soil. The difference in $0-1-\mathrm{km}$ wind shear is associated mostly with wind speed differences; the directional shear differences between ensembles are negligible. More specifically, GPLLJ wind speed differences cause the observed interensemble $0-1-\mathrm{km}$ wind shear differences. At 0900 UTC, the GPLLJ at $850 \mathrm{hPa}$ is $1-4 \mathrm{~m} \mathrm{~s}^{-1}$ slower over wet soil compared to dry soil. However, near-surface winds are generally the same over wet and dry soils. Additional analyses (not shown) reveals the interensemble wind shear differences are limited to the first two kilometers above ground level during the early morning hours of 21 July 2017. The upper-level winds above $2 \mathrm{~km}$, along with the near-surface winds, are comparable under both soil moisture conditions (Fig. 6).

\section{f. Geostrophic and ageostrophic wind components}

Meaningful mass field contrasts start to develop between the wet and dry soil ensembles from 1500 to 2100 UTC (daytime) 20 July 2017 and continue to strengthen into the night as determined through analysis of 850-hPa geopotential heights and temperatures (not shown). The wet ensemble has higher geopotential heights and lower temperatures than the dry ensemble. Prior to 0000 UTC 21 July 2017 (simulation hour 24) the magnitude of the $850-\mathrm{hPa}$ geopotential height differences between the wet and dry ensembles are limited and generally less than 0.5 dam (not shown). Mass field adjustments, while consistent in sign, do not become statistically significant until approximately $24 \mathrm{~h}$ into the simulation as the mass field differences require time to grow despite temperature differences forming much earlier. Moreover, interensemble differences in $850-\mathrm{hPa}$ geopotential height and temperature fields are confined to the GP at all times.

By 0900 UTC 21 July 2017 (Figs. 10a-f), temperature and geopotential height fields at $850 \mathrm{hPa}$ depict cooler temperatures $\left(\sim 0.5^{\circ}-2^{\circ} \mathrm{C}\right)$ and higher geopotential heights $(\sim 0.2-0.5 \mathrm{dam})$ in the GP over wet soil as compared to dry soil. The $850-\mathrm{hPa}$ mass fields of both ensembles show a relative minimum in geopotential height ( $\sim 146-148$ dam) corresponding to a relative maximum in 850-hPa temperature $\left(\sim 26^{\circ}-28^{\circ} \mathrm{C}\right)$ (Figs. 10a-f) under an upper-level ridge (not shown) in the northern GP, indicating that a thermal low is present. The thermal low initially forms in the northwestern GP during the daytime and strengthens until early morning, increasing the 

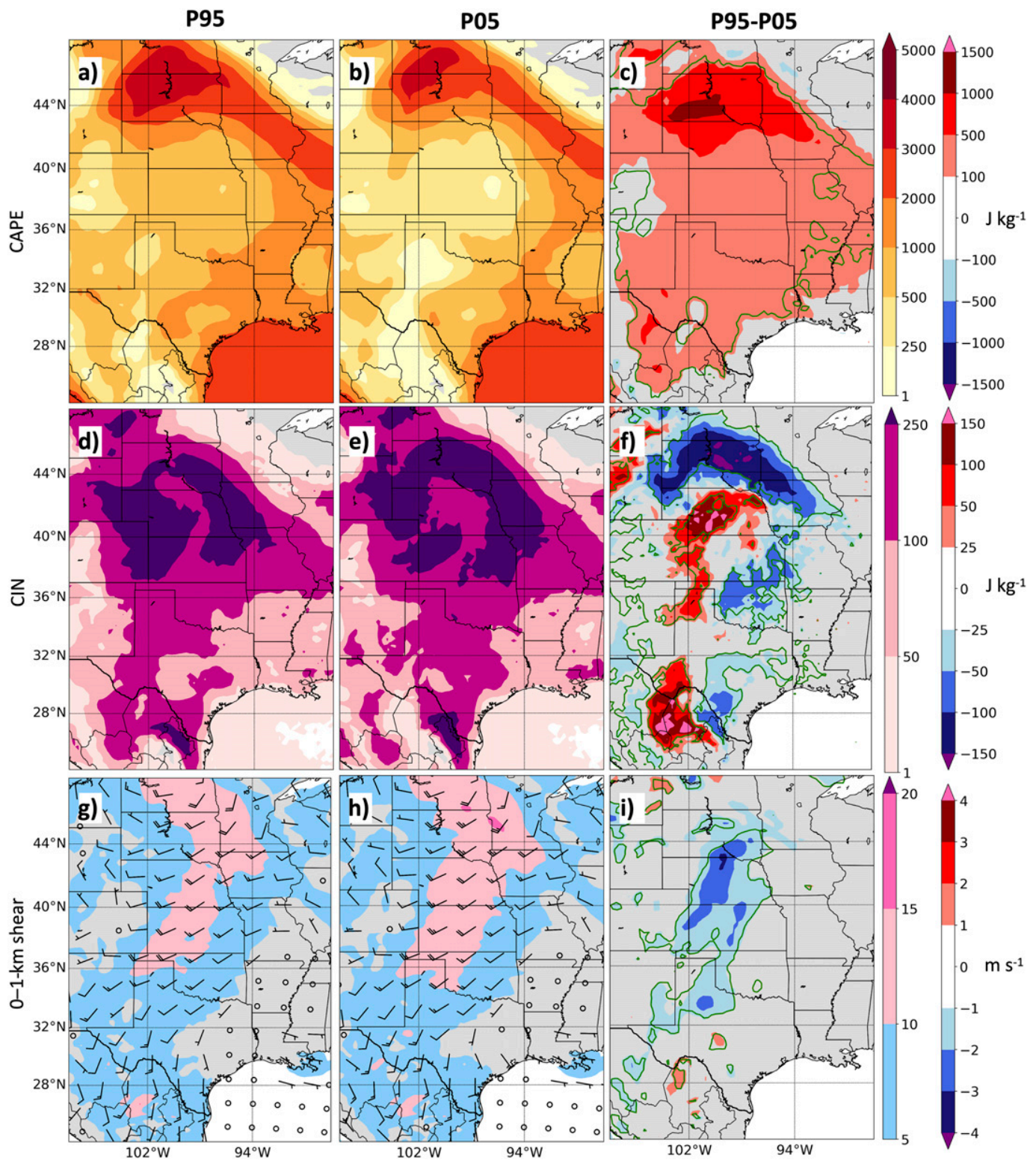

FIG. 9. (a) WRF-derived mean CAPE (shaded; $\mathrm{J} \mathrm{kg}^{-1}$ ) for the wet ensemble at $0900 \mathrm{UTC} 21 \mathrm{Jul}$ 2017. (b) As in (a), but for dry ensemble. (c) Difference between wet and dry ensemble mean CAPE (shaded; $\mathrm{J} \mathrm{kg}^{-1}$ ). Solid green outline denotes regions where difference of means $t$ test for CAPE is statistically significant $(p \leq 0.05)$. (d) WRFderived mean CIN (shaded; $\mathrm{J} \mathrm{kg}^{-1}$ ) for the wet ensemble at 0900 UTC $21 \mathrm{Jul}$ 2017. (e) As in (d), but for dry ensemble. (f) As in (c), but for CIN $\left(\mathrm{J} \mathrm{kg}^{-1}\right)$. (g) Mean 0-1-km wind shear magnitude (shaded; $\mathrm{m} \mathrm{s}^{-1}$ ) and shear vectors (barbs; $\mathrm{m} \mathrm{s}^{-1}$ ) for the wet ensemble at 0900 UTC 21 Jul 2017. (h) As in (g), but for dry ensemble. (i) As in (c), but for 0-1-km wind shear magnitude $\left(\mathrm{m} \mathrm{s}^{-1}\right)$. Land is shaded in gray and oceans are white. Values from -100.0 to $100.0 \mathrm{~J} \mathrm{~kg}^{-1}$ (CAPE), -25.0 to $25.0 \mathrm{~J} \mathrm{~kg}^{-1}$ (CIN), and -1.0 to $1.0 \mathrm{~m} \mathrm{~s}^{-1}$ (0-1-km shear) (small differences) in the difference plots are not shaded.

geopotential height gradient in the GP, as the low drifts eastward (not shown). The thermal low deepens more quickly over dry soil as more heat accumulates throughout the daytime in the PBL and the residual boundary layer remains warmer overnight.

To quantify the impact of the thermal low on the GPLLJ total wind, the geostrophic wind is calculated on the 850-hPa pressure level for each individual ensemble member and averaged across 31 members for each ensemble mean. These calculations reveal that the southwesterly $850-\mathrm{hPa}$ geostrophic wind can explain most of the southwesterly GPLLJ total wind as the wind barbs and location of the total winds closely resemble the geostrophic wind field over the course of the simulation 

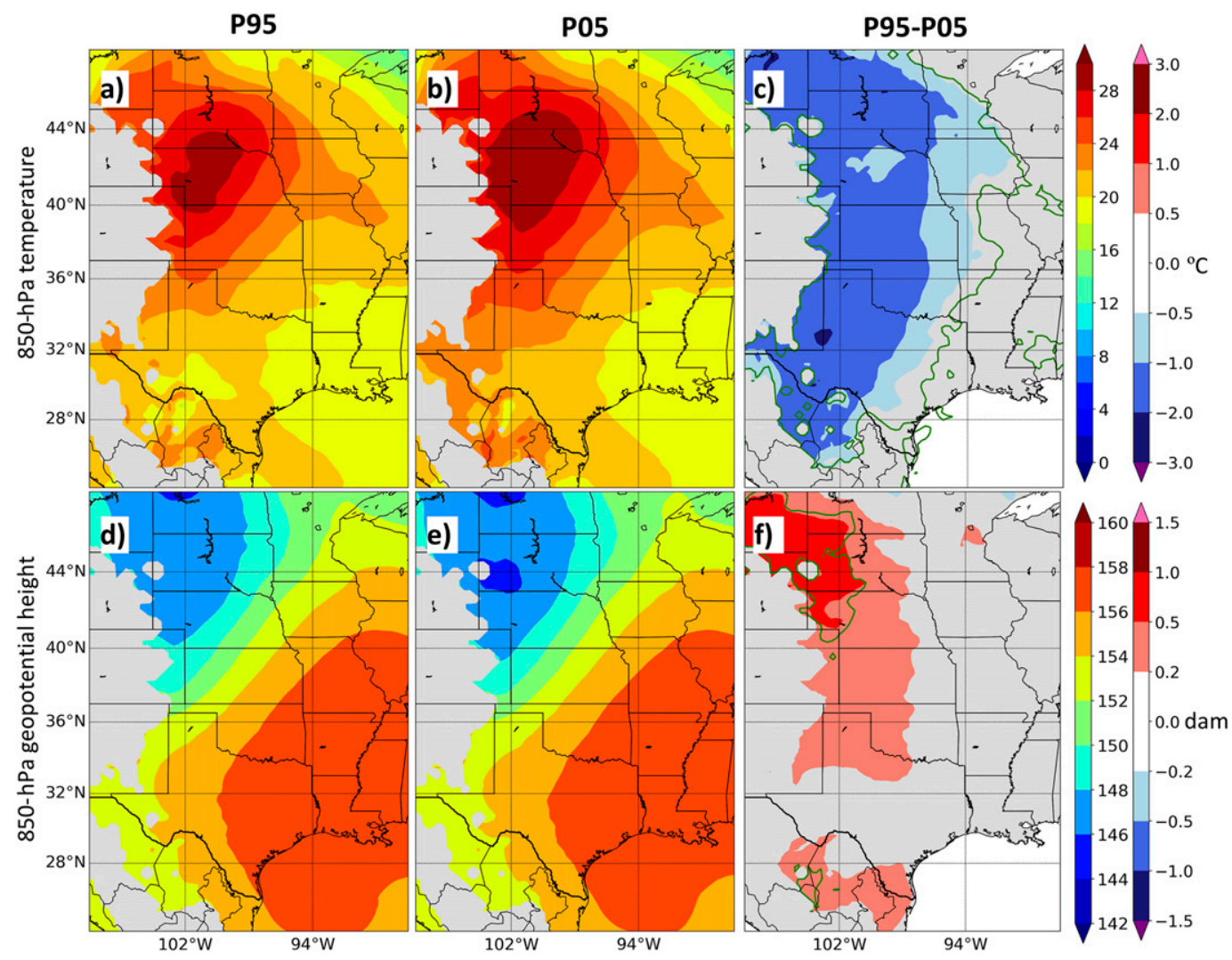

FIG. 10. (a) WRF-derived mean 850-hPa temperature (shaded; ${ }^{\circ} \mathrm{C}$ ) for the wet ensemble at 0900 UTC 21 Jul 2017. (b) As in (a), but for dry ensemble. (c) Difference between wet and dry ensemble mean 850-hPa temperature (shaded; ${ }^{\circ} \mathrm{C}$ ). Solid green outline denotes regions where difference of means $t$ test for ensemble 850-hPa temperature is statistically significant $(p \leq 0.05)$. (d) Mean $850-\mathrm{hPa}$ geopotential height (shaded; dam) for the wet ensemble at 0900 UTC 21 Jul 2017. (e) As in (d), but for dry ensemble) (f) As in (c), but for geopotential height (dam). Land is shaded in gray and oceans are white. Values from $-0.5^{\circ}$ to $0.5^{\circ} \mathrm{C}(850-\mathrm{hPa}$ temperature $)$ and -0.2 to 0.2 dam (850-hPa geopotential height) (small differences) in the difference plots are not shaded.

(Figs. 5d,e, 11a,b, and 12). The total wind speed evolution is also similar to the geostrophic wind speed evolution as both increase as the thermal low deepens (not shown). However, the geostrophic wind does not veer significantly overnight, indicating that the nocturnal veering of the GPLLJ total winds are not associated with the geostrophic wind (Fig. 12). Additionally, the increase of the GPLLJ total wind from 0000 to 0600 UTC cannot be fully attributed to the geostrophic wind because the geostrophic wind does not accelerate as rapidly as the total wind.

Geostrophic wind speed difference analysis between ensembles at $850-\mathrm{hPa}$ reveals enhancement of the southwesterly geostrophic wind over dry soil compared to wet soil by approximately $0-2 \mathrm{~m} \mathrm{~s}^{-1}$ from 1800 UTC 20 July 2017 onward. It is important to note interensemble geostrophic wind speed differences form $12 \mathrm{~h}$ prior to widespread total GPLLJ wind speed differences appearing. At night (0900 UTC 21 July 2017), when the interensemble GPLLJ total wind speed differences are largest, the greatest $850-\mathrm{hPa}$ geostrophic wind speed differences occur in the northern GP, on the western end of the GPLLJ exit region (Figs. 5d,e). In this same region, the $850 \mathrm{hPa}$ total wind speed differences are approximately $1-4 \mathrm{~m} \mathrm{~s}^{-1}$ (Fig. 5f). The deeper thermal low in the dry soil ensemble is serving to maintain a wider, longer, and more pronounced GPLLJ, as evidenced by an expanded area of geostrophic wind exceeding $15 \mathrm{~m} \mathrm{~s}^{-1}$ over Kansas, Nebraska, and South Dakota (Figs. 11a-c). There is some evidence of enhancement in the geostrophic wind across the rest of the GP over dry soil at 0900 UTC but the interensemble differences in GPLLJ total winds, particularly in the southern GP, cannot be adequately explained by the geostrophic wind/mass fields. The ageostrophic wind must also be considered.

The ageostrophic wind component, which we use as a rough proxy to describe the inertial oscillation 


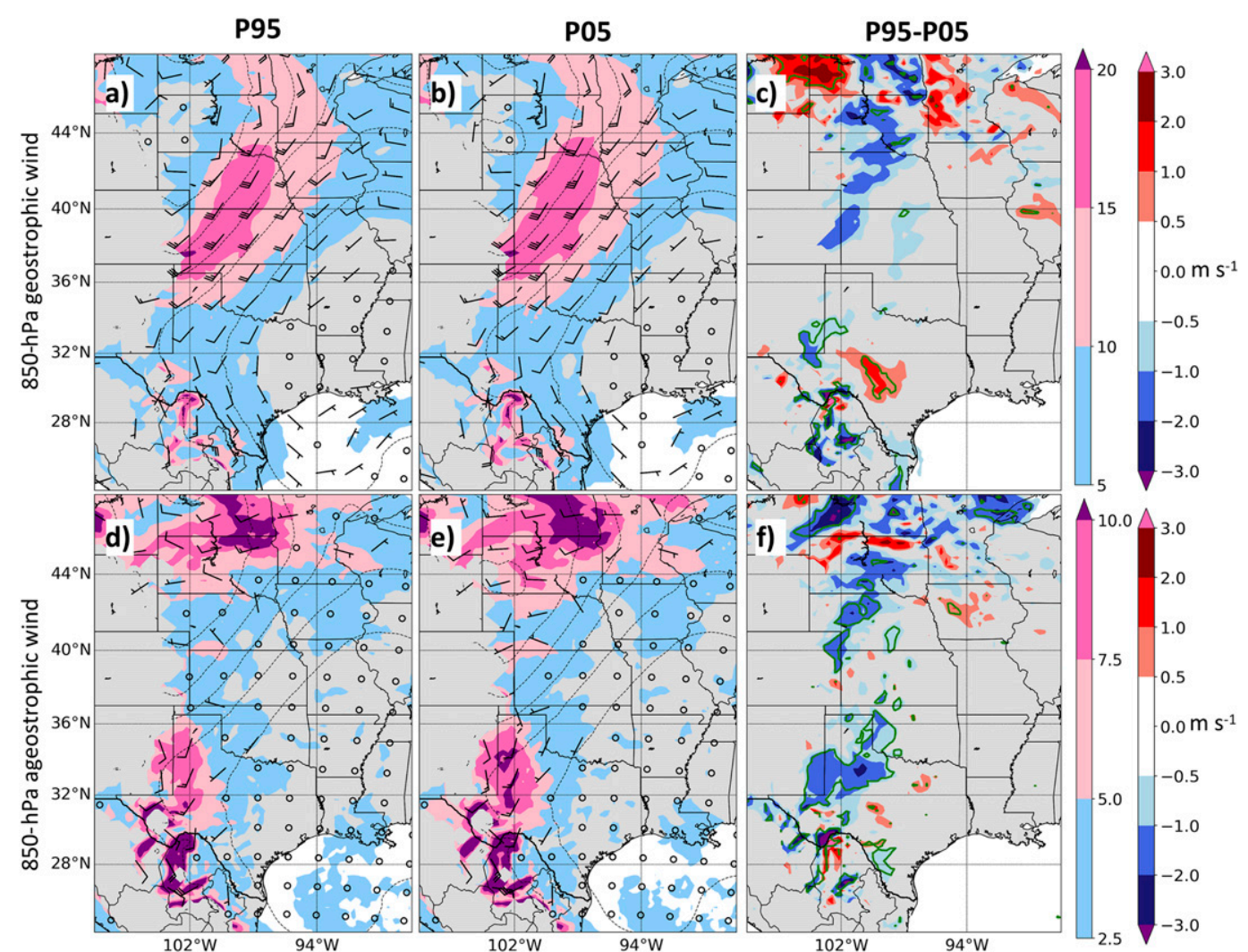

FIG. 11. (a) WRF-derived mean 850-hPa geostrophic wind speed (shaded; $\mathrm{m} \mathrm{s}^{-1}$ ), geostrophic wind vectors (barbs; $\mathrm{m} \mathrm{s}^{-1}$ ), and geopotential height (dashed contours; every 2 dam) for the wet ensemble at 0900 UTC 21 Jul 2017. (b) As in (a), but for dry ensemble. (c) Difference between wet and dry ensemble mean 850-hPa geostrophic wind speed (shaded; $\mathrm{m} \mathrm{s}^{-1}$ ) and geostrophic wind vectors (barbs; $\mathrm{m} \mathrm{s}^{-1}$ ). Solid green outline denotes regions where difference of means $t$ test for ensemble 850-hPa geostrophic wind speed is statistically significant $(p \leq 0.05)$. (d) As in (a), but for ageostrophic wind. (e) As in (b), but for ageostrophic wind. (f) As in (c), but for ageostrophic wind $\left(\mathrm{m} \mathrm{s}^{-1}\right)$. Land is shaded in gray and oceans are white. Values from -0.5 to $0.5 \mathrm{~m} \mathrm{~s}^{-1}$ (small differences) in the difference plots are not shaded.

(e.g., Blackadar 1957), is calculated by subtracting the geostrophic wind from the total wind field at $850 \mathrm{hPa}$ for each ensemble member and then averaged across ensemble members accordingly. Ageostrophic wind speed difference analysis between ensembles at $850-\mathrm{hPa}$ reveals that ageostrophic wind speed differences appear around the same time as geostrophic wind speed differences. By 1800 UTC 20 July 2017 (not shown), the ageostrophic wind magnitude is $1-2 \mathrm{~m} \mathrm{~s}^{-1}$ smaller over wet soil compared to dry soil in the GP. Ageostrophic wind speed differences between ensembles remain similar in magnitude throughout the afternoon and nighttime as the total wind speed differences grow from 0000 to 0900 UTC. When total GPLLJ wind speed differences are largest at 0900 UTC, the $850-\mathrm{hPa}$ ageostrophic wind is $1-2 \mathrm{~m} \mathrm{~s}^{-1}$ faster over dry soil compared to wet soil in the GPLLJ entrance region and western end of the GPLLJ exit region in the northern GP (Figs. 11d-f). While not statistically significant everywhere, the ageostrophic wind over dry soil is generally greater in magnitude than over wet soil in the vicinity of the GPLLJ and helps contribute to the faster southeasterly GPLLJ over dry soil during the nighttime hours due to the direction of the ageostrophic wind.

Figure 12 provides a diurnal hodograph analysis of the total, geostrophic, and ageostrophic winds at the exit, core, and entrance regions of the GPLLJ. The hodographs show the daytime $850-\mathrm{hPa}$ ageostrophic wind, which is influenced by friction in the convective PBL, has northerly and easterly components in the GP that are opposing the geostrophic wind, leading to subgeostrophic total winds. Over the course of the day, the ageostrophic wind rotates clockwise, strengthens around sunset, and develops southerly and westerly components overnight as the ageostrophic causes the total winds to veer. During the night, the ageostrophic wind roughly aligns with the geostrophic wind from 0600 to 1200 UTC 21 July 2017 leading to 

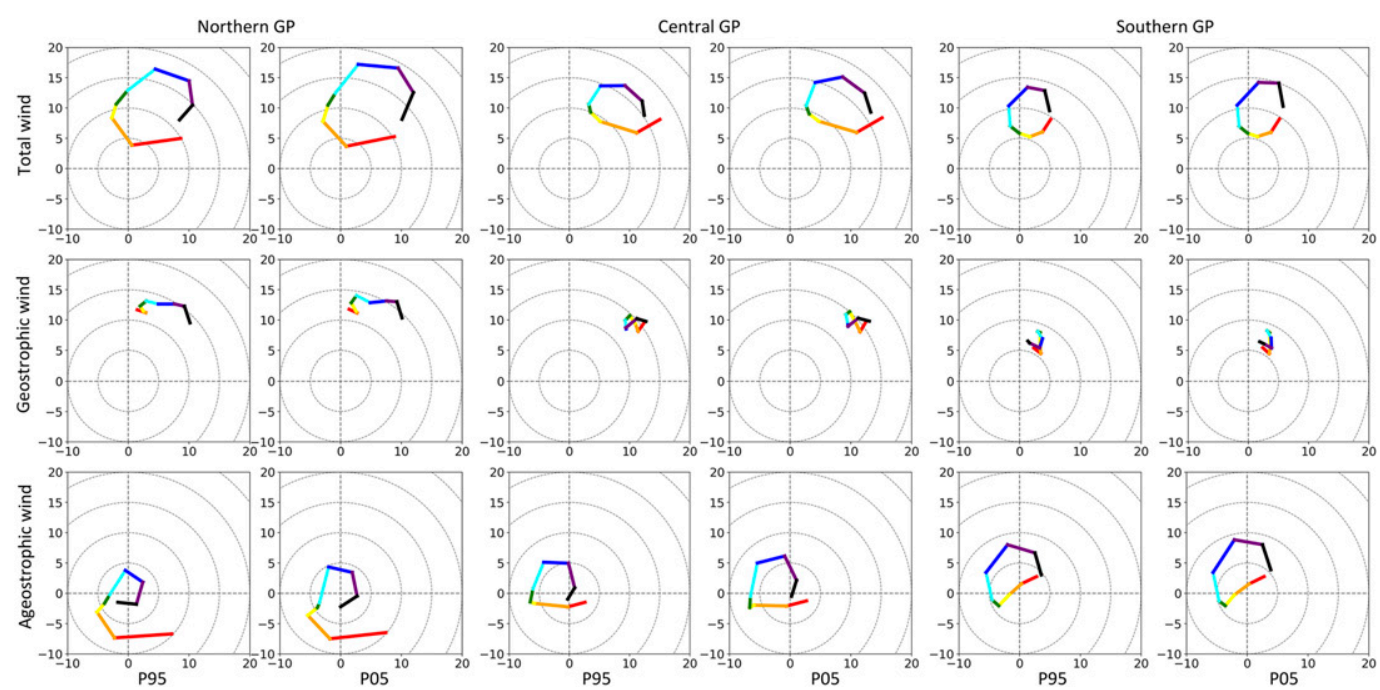

FIG. 12. Spatially averaged hodographs $\left(\mathrm{m} \mathrm{s}^{-1}\right)$ in the northern, central, and southern GP at 850-hPa for the total wind, geostrophic wind, and ageostrophic wind from 1200 UTC 20 Jul-1200 UTC 21 Jul 2017. Red: 1200-1500 UTC 20 Jul 2017, orange: 1500-1800 UTC 20 Jul 2017, yellow: 1800-2100 UTC 20 Jul 2017, green: 2100 UTC 200000 UTC 21 Jul 2017, aqua: 0000-0300 UTC 21 Jul 2017, blue: 0300-0600 UTC 21 Jul 2017, purple 0600-0900 UTC 21 Jul 2017, black: 0900-1200 UTC 21 Jul 2017.

supergeostrophic total winds (Fig. 12). For example, at 0900 UTC, the southerly/westerly ageostrophic winds contribute $\sim 5-10 \mathrm{~m} \mathrm{~s}^{-1}$ to the total wind over the southern GP. Elsewhere, such as near the core of the GPLLJ in the central GP, the ageostrophic contribution to the GPLLJ total wind is between 0 and $5 \mathrm{~m} \mathrm{~s}^{-1}$ (Figs. 11d-f). Furthermore, the ageostrophic wind rotates $\sim 180^{\circ}$ clockwise over $12 \mathrm{~h}$ overnight. This is characteristic of an inertial oscillation which has a period of $24 \mathrm{~h}$ at $30^{\circ} \mathrm{N}$. The veering in the total wind field closely matches that of the ageostrophic wind field (Fig. 12).

It may seem counterintuitive that the GPLLJ 850-hPa total wind speed differences are only apparent from 0600 to 1200 UTC 21 July 2017 despite the geostrophic and ageostrophic wind magnitudes being greater over dry soil compared to wet soil by 1800 UTC 20 July 2017 (not shown). To understand the temporal evolution of the total wind speed, the directions of the geostrophic and ageostrophic winds, in addition to their magnitudes, must be considered. During the afternoon ( $\sim 2100$ UTC), the southwesterly geostrophic winds are faster over dry soil. At the same time, the easterly/northeasterly ageostrophic wind, which opposes the geostrophic wind, is also faster over dry soil. When computing the total wind, which is subgeostrophic during the day, any gain to the total wind speed over dry soil from the faster southwesterly geostrophic wind is offset by increased northeasterly ageostrophic wind opposing the geostrophic wind. The result is interensemble $850-\mathrm{hPa}$ total wind speeds remaining comparable in the afternoon. However, the ageostrophic wind veers as the afternoon and evening progresses (total wind field also veers). By 0900 UTC (nighttime), the ageostrophic wind is southerly/westerly, which is the same direction as the southwesterly geostrophic wind (Fig. 12) leading to supergeostrophic winds. Addition of the higher magnitude, similar direction, geostrophic and ageostrophic winds over dry soil results in faster southwesterly $850-\mathrm{hPa}$ total wind compared to wet soil. When the geostrophic and ageostrophic wind directions are less than $90^{\circ}$ apart from 0600 to 1200 UTC 21 July 2017 (Fig. 12), the interensemble wind speed differences in the geostrophic and ageostrophic winds are in the same direction leading to the largest GPLLJ total wind speed differences. During the day, geostrophic and ageostrophic wind directions or more than $90^{\circ}$ apart, which causes wind component differences to cancel out.

\section{Discussion and conclusions}

\section{a. Ageostrophic wind dynamics}

The increase in the 850-hPa ageostrophic wind over dry soil compared to wet soil is dynamically important. According to Shapiro and Fedorovich (2010), increased diurnal differences in turbulent exchange is dynamically linked to stronger GPLLJs. Markowski and Richardson (2010) similarly demonstrate the magnitude of the nocturnal inertial oscillation associated with the GPLLJ is related to the magnitude of the ageostrophic wind during the daytime before inertial oscillation formation. 
It is hypothesized that the dynamical linkage between the nocturnal $850-\mathrm{hPa}$ ageostrophic wind differences over wet and dry soil is driven by larger diurnal reductions in turbulent exchange, or equivalently, increased daytime ageostrophic wind, over dry soil compared to wet soil.

To support this claim, we attempt to physically relate turbulent exchange to surface heat fluxes and PBL structure. Daytime PBL structure, as represented by $\mathrm{PBLH}$, is related to surface heat fluxes. Sensible heating in particular, which is influenced by soil moisture, can be important in determining the PBLH (e.g., Ek and Mahrt 1994). Greater sensible heating occurs over dry soil in GP $\left(\sim 25-150 \mathrm{~W} \mathrm{~m}^{-2}\right)$. Greater sensible heating leads to deeper and more rapid increases in PBLH during the day over dry soil compared to wet soil. The increased rate of PBL growth over dry soil is likely due to deeper and stronger turbulent eddies (i.e., turbulent exchange) resulting from increased convective turbulence over the warmer dry soil surface during the daytime. At night, surface fluxes in both ensembles approach zero in the absence of insolation and turbulent mixing weakens. The PBL collapses after sunset, as evidenced by PBLH values decreasing (not shown). Since surface fluxes and PBLH at night are nearly identical in both ensemble groups, it is hypothesized that nighttime turbulent exchange in each ensemble is comparable as well. Thus, maximum daytime values, rather than minimum nighttime values, of turbulent exchange determine the diurnal range of turbulent exchange.

Over dry soil, the turbulent exchange during the daytime is larger than over wet soil, as evidenced by larger magnitudes of northeasterly/easterly ageostrophic wind vectors, which are opposing the geostrophic wind due to friction, at 2100 and 0000 UTC (not shown). Consequentially, the diurnal difference in turbulent exchange is larger over dry soil and the daytime departure from geostrophy, which controls the amplitude of the inertial oscillation, is larger over dry soil compared to wet soil. The result is a stronger nocturnal southwesterly ageostrophic component (associated with the inertial oscillation) to the flow over dry soil in the GP at $850 \mathrm{hPa}$, especially in the western GP where $850-\mathrm{hPa}$ pressure level is closer to the ground and most impacted by surface friction during the day.

\section{b. GPLLJ formation mechanisms}

The Blackadar (1957) mechanism for GPLLJ formation is clearly impacted by altered PBL structure over wet and dry soil. Dry soil simulations exhibit more sensible heating in the GP compared to wet soil during the daytime leading to warmer lower-tropospheric conditions and stronger turbulent eddies associated with a deeper PBL. Upon nightfall, the PBL, along with turbulent exchange, collapses in both simulations allowing the inertial oscillation to form as evidenced by accelerating and veering ageostrophic winds at night. Larger differences in diurnal turbulent exchange occur over dry soil, along with increased ageostrophic winds at the time of the PBL collapse, support the stronger $850-\mathrm{hPa}$ ageostrophic response over dry soil, or a stronger inertial oscillation, to first order.

It is arguable to what extent the classic Holton mechanism (1967) is applicable in this case since the geopotential height gradient, and the corresponding geostrophic wind field, in the GP is strongest at approximately 0900 UTC. Parish and Oolman (2010) demonstrate that the geopotential height gradient, and geostrophic wind, associated with the classic Holton mechanism should instead peak around sunset $(\sim 0000$ UTC). The geopotential height evolution in this case study differs from the classic Holton mechanism primarily due to the thermal low in the northern GP. Geostrophic winds and geopotential height gradients strengthen well after sunset and are maximized at night when thermal low is deepest, not necessarily when temperature gradients are maximized. Increased heating in the GP over dry soil results in faster geostrophic winds due to the thermal low deepening more rapidly over dry soil compared to wet soil.

Despite the thermal low leading to differences in the temporal evolution of the geopotential height gradients from the Holton mechanism presented by Parish and Oolman (2010), some evidence exists that the Holton mechanism is contributing to the diurnal evolution of the wind field. Cross sections from the afternoon and nighttime reveal lower-tropospheric east-west temperature gradients are impacted by soil moisture as the wet soil simulation has cooler near-surface temperatures than the dry soil simulation. The east-west temperature gradient reverses from day to night in the lower troposphere within approximately $1 \mathrm{~km}$ above the ground which can help provide thermal wind forcing for GPLLJ development considering the GPLLJ resides west of the lower-tropospheric temperature maximum (Fig. 6). Based on the results of this case study, it is proposed that the operable physical mechanisms necessary to fully understand the observed soil moisture-driven GPLLJ differences are in decreasing order of importance: 1) Blackadar mechanism, 2) synoptic-scale circulations associated with the structure and evolution of the GP thermal low, and 3) diurnally varying circulations associated with the Holton mechanism.

\section{c. Conclusions}

This study indicates that the GPLLJ can be impacted by regional soil moisture conditions. The GPLLJ sensitivity 
to soil moisture is tested by initializing WRF with two distinct soil moisture anomaly profiles. The 95th percentile of soil moisture values from the modeled 19822016 daily warm season climatology represents wet soil conditions, while the 5 th percentile represents dry soil conditions. Between 0600 and 1200 UTC 21 July 2017, GPLLJ $850-\mathrm{hPa}$ winds are modeled to be $1-4 \mathrm{~m} \mathrm{~s}^{-1}$ faster in the entrance and exit regions of the GPLLJ over dry soil when compared to wet soil, leading to a wider and longer GPLLJ. Wind speed differences at $850 \mathrm{hPa}$ prior to 0600 UTC 21 July 2017, and after 1200 UTC, are not statistically different and are less than $1 \mathrm{~m} \mathrm{~s}^{-1}$. The lower-tropospheric wind speed was only impacted by soil moisture between tens of meters to $2 \mathrm{~km}$ above ground level.

The dynamical drivers of the two distinct GPLLJ responses over wet and dry soil are daytime surface sensible and latent heat fluxes. Greater sensible heat flux ranging from $25-150 \mathrm{~W} \mathrm{~m}^{-2}$, along with less latent heat flux, is modeled over dry soil compared to wet soil in the GP. It is hypothesized that deeper and stronger turbulent eddies form over dry soil in response to greater sensible heat flux compared to wet soil. A warmer, drier, and deeper PBL results. Consequentially, warmer lowertropospheric conditions over dry soil lead to enhanced thermal low development overnight in the northern GP. The mass-field response increases $850-\mathrm{hPa}$ southwesterly geostrophic wind over dry soil compared to wet soil by $0-2 \mathrm{~m} \mathrm{~s}^{-1}$ from $\sim 1800$ UTC $20-1200$ UTC 21 July 2017. Diurnally dependent ageostrophic flow (northerly/easterly during day; westerly/southerly during night) at $850 \mathrm{hPa}$ is also enhanced by $0-2 \mathrm{~m} \mathrm{~s}^{-1}$ over dry soil due to increased friction during the day and a stronger inertial oscillation at night. The increased geostrophic and ageostrophic wind align closely at night ultimately leading to a stronger GPLLJ over dry soil from 0600 to 1200 UTC 21 July 2017. During the day, the geostrophic and ageostrophic wind directions appose each other which helps to reduce 850-hPa wind differences below $1 \mathrm{~m} \mathrm{~s}^{-1}$.

Surface heat fluxes and the GPLLJ also drive changes in the thermodynamic and kinematic fields that are often analyzed when forecasting severe weather. CAPE values are larger in the GP in the wet soil ensemble at all times by $500-1000 \mathrm{~J} \mathrm{~kg}^{-1}$. The $0-1-\mathrm{km}$ wind shear between 0600 and 1200 UTC 21 July 2017 is $1-3 \mathrm{~m} \mathrm{~s}^{-1}$ greater over dry soil due to a stronger GPLLJ over dry soil. While it is difficult to determine whether dry or wet soil conditions more favor severe storms, shifts in the CAPE and wind shear profiles can occur. Changes in CAPE and shear could have important impacts on the degree of convective organization and strength of storms between dry and wet soil simulations (e.g., Rotunno et al. 1988).
Future work can leverage the experimental design used in this study to investigate sensitivity of the GPLLJ to less extreme soil moisture scenarios, different vegetative growth states, and to isolate source regions of soil moisture-GPLLJ sensitivity. The role of the different model physics parameterizations (incl., PBL and land surface), land data assimilation, and horizontal model resolution can also be investigated. Additionally, the impact of the strength of land-atmospheric coupling relative to the strength of the GPLLJ-upper-level jet stream coupling on wet and dry soil moisture scenarios could be investigated. A long-term objective dynamic classification of GPLLJ upper-level coupling for the twentieth century developed by Burrows et al. (2019) could be helpful in this regard.

Acknowledgments. This research was supported by NSF Award AGS-1638936 and NASA Award NNX16AM13G. MERRA-2 data (tavg1_2d_lfo_Nx and inst1_2d_asm_Nx; doi:10.5067/L0T5GEG1NYFA) was obtained from the NASA Goddard Earth Sciences (GES) Data and Information Services Center (DISC) via Earthdata (https://earthdata.nasa.gov/). ERAInterim data were obtained via the Research Data Archive at the National Center for Atmospheric Research (https://rda.ucar.edu/datasets/ds627.0/). The authors thank Robert Fovell, Ryan Torn, Ariel Cohen, Matthew Vaughan, and Tomer Burg for discussions and technical aid that contributed to this work. The authors are appreciative of the helpful comments and important insights provided by the three reviewers, two of whom were anonymous and one of whom signed his review (Tom Parish). We are also appreciative about how MWR Editor Stan Trier handled the review process.

\section{REFERENCES}

AWEA, 2018: Wind facts at a glance. American Wind Energy Association, accessed 25 April 2019, https://www.awea.org/ wind-101/basics-of-wind-energy/wind-facts-at-a-glance.

Basara, J. B., J. N. Maybourn, C. M. Peirano, J. E. Tate, P. J. Brown, J. D. Hoey, and B. R. Smith, 2013: Drought and associated impacts in the Great Plains of the United States-A review. Int. J. Geosci., 4, 72-81, https://doi.org/10.4236/ ijg.2013.46A2009.

Bell, G. D., and L. F. Bosart, 1988: Appalachian cold air damming. Mon. Wea. Rev., 116, 137-161, https://doi.org/10.1175/15200493(1988)116<0137:ACAD>2.0.CO;2.

Berg, L. K., L. D. Riihimaki, Y. Qian, H. Yan, and M. Huang, 2015: The low-level jet over the southern Great Plains determined from observations and reanalyses and its impact on moisture transport. J. Climate, 28, 6682-6706, https://doi.org/10.1175/ JCLI-D-14-00719.1.

Berner, J., S.-Y. Ha, and J. Hacker, 2011: Model uncertainty in a mesoscale ensemble prediction system: Stochastic versus multiphysics representations. Mon. Wea. Rev., 139, 1972-1995, https://doi.org/10.1175/2010MWR3595.1. 
— K. R. Fossell, S.-Y. Ha, J. P. Hacker, and C. Snyder, 2015: Increasing the skill of probabilistic forecasts: Understanding performance improvements from model-error representations. Mon. Wea. Rev., 143, 1295-1320, https://doi.org/10.1175/ MWR-D-14-00091.1.

Blackadar, A. K., 1957: Boundary-layer wind maxima and their significance for the growth of nocturnal inversions. Bull. Amer. Meteor. Soc., 38, 283-290, https://doi.org/10.1175/15200477-38.5.283.

Bonner, W. D., 1968: Climatology of the low-level jet. Mon. Wea. Rev., 96, 833-850, https://doi.org/10.1175/1520-0493(1968) 096<0833:COTLLJ $>2.0$. CO;2.

Burrows, D. A., C. R. Ferguson, M. A. Campbell, G. Xia, and L. F. Bosart, 2019: An objective classification and analysis of upperlevel coupling to the Great Plains low-level jet over the twentieth century. J. Climate, 32, 7127-7152, https://doi.org/ 10.1175/JCLI-D-18-0891.1.

Case, J. L., S. V. Kumar, J. Srikishen, and G. J. Jedlovec, 2011: Improving numerical weather predictions of summertime precipitation over the southeastern United States through a highresolution initialization of the surface state. Wea. Forecasting, 26, 785-807, https://doi.org/10.1175/2011WAF2222455.1.

Coniglio, M. C., J. Y. Hwang, and D. J. Stensrud, 2010: Environmental factors in the upscale growth and longevity of MCSs derived from rapid update cycle analyses. Mon. Wea. Rev., 138, 3514-3539, https://doi.org/10.1175/2010MWR3233.1.

Cotton, W. R., M. S. Lin, R. L. McAnelly, and C. J. Tremback, 1989: A composite model of mesoscale convective complexes. Mon. Wea. Rev., 117, 765-783, https://doi.org/10.1175/15200493(1989)117<0765:ACMOMC > 2.0.CO;2.

Dee, D. P., and Coauthors, 2011: The ERA-Interim reanalysis: Configuration and performance of the data assimilation system. Quart. J. Roy. Meteor. Soc., 137, 553-597, https://doi.org/ 10.1002/qj.828.

Dirmeyer, P. A., and K. L. Brubaker, 1999: Contrasting evaporative moisture sources during the drought of 1988 and the flood of 1993. J. Geophys. Res., 104, 19383-19397, https://doi.org/ 10.1029/1999JD900222.

Doubler, D. L., J. A. Winkler, X. Bian, C. K. Walters, and S. Zhong, 2015: An NARR-derived climatology of southerly and northerly low-level jets over North America and coastal environs. J. Appl. Meteor. Climatol., 54, 1596-1619, https:// doi.org/10.1175/JAMC-D-14-0311.1.

Du, Y., and R. Rotunno, 2014: A simple analytical model of the nocturnal low-level jet over the Great Plains of the United States. J. Atmos. Sci., 71, 3674-3683, https://doi.org/10.1175/ JAS-D-14-0060.1.

Ek, M. B., and L. Mahrt, 1994: Daytime evolution of relative humidity at the boundary layer top. Mon. Wea. Rev., 122, 2709-2721, https://doi.org/10.1175/1520-0493(1994)122<2709: DEORHA $>2.0 . \mathrm{CO} ; 2$.

—_, and A. A. M. Holtslag, 2004: Influence of soil moisture on boundary layer cloud development. J. Hydrometeor., 5, 86-99, https://doi.org/10.1175/1525-7541(2004)005<0086: IOSMOB $>2.0 . \mathrm{CO} ; 2$.

—_, K. E. Mitchell, Y. Lin, E. Rogers, P. Grunmann, V. Koren, G. Gayno, and J. D. Tarpley, 2003: Implementation of Noah land surface model advances in the National Centers for Environmental Prediction operational mesoscale Eta Model. J. Geophys. Res., 108, 8851, https://doi.org/10.1029/ 2002JD003296.

Fast, J. D., and M. D. McCorcle, 1990: A two-dimensional numerical sensitivity study of the Great Plains low-level jet. Mon. Wea.
Rev., 118, 151-164, https://doi.org/10.1175/1520-0493(1990) $118<0151$ :ATDNSS $>2.0$.CO;2.

Fedorovich, E., J. A. Gibbs, and A. Shapiro, 2017: Numerical study of nocturnal low-level jets over gently sloping terrain. J. Atmos. Sci., 74, 2813-2834, https://doi.org/10.1175/JAS-D-17-0013.1.

Fischer, E. M., S. Seneviratne, P. Vidale, D. Lüthi, and C. Schär, 2007: Soil moisture atmosphere interactions during the 2003 European summer heat wave. J. Climate, 20, 5081-5099, https://doi.org/10.1175/JCLI4288.1.

French, A. J., and M. D. Parker, 2010: The response of simulated nocturnal convective systems to a developing lowlevel jet. J. Atmos. Sci., 67, 3384-3408, https://doi.org/ 10.1175/2010JAS3329.1.

Gelaro, R., and Coauthors, 2017: The Modern-Era Retrospective Analysis for Research and Applications, Version 2 (MERRA-2). J. Climate, 30, 5419-5454, https://doi.org/10.1175/JCLI-D16-0758.1.

Gesch, D. B., K. L. Verdin, and S. K. Greenlee, 1999: New land surface digital elevation model covers the Earth. Eos, Trans. Amer. Geophys. Union, 80, 69-70, https://doi.org/10.1029/ 99EO00050.

Guo, Z., and Coauthors, 2006: GLACE: The Global LandAtmosphere Coupling Experiment. Part II: Analysis. J. Hydrometeor., 7, 611-625, https://doi.org/10.1175/JHM511.1.

Helfand, H. M., and S. D. Schubert, 1995: Climatology of the simulated Great Plains low-level jet and its contribution to the continental moisture budget of the United States. J. Climate, 8, 784-806, https://doi.org/10.1175/1520-0442(1995) 008<0784:COTSGP $>2.0 . \mathrm{CO} ; 2$.

Higgins, R., Y. Yao, E. Yarosh, J. Janowiak, and K. Mo, 1997: Influence of the Great Plains low-level jet on summertime precipitation and moisture transport over the central United States. J. Climate, 10, 481-507, https://doi.org/10.1175/15200442(1997)010<0481:IOTGPL > 2.0.CO;2.

Hoerling, M., J. Eischeid, A. Kumar, R. Leung, A. Mariotti, K. Mo, S. Schubert, and R. Seager, 2014: Causes and predictability of the 2012 Great Plains drought. Bull. Amer. Meteor. Soc., 95, 269-282, https://doi.org/10.1175/BAMS-D-13-00055.1.

Holton, J. R., 1967: The diurnal boundary layer wind oscillation above sloping terrain. Tellus, 19, 199-205, https://doi.org/ 10.1111/j.2153-3490.1967.tb01473.x.

Hong, S.-Y., Y. Noh, and J. Dudhia, 2006: A new vertical diffusion package with an explicit treatment of entrainment processes. Mon. Wea. Rev., 134, 2318-2341, https://doi.org/10.1175/MWR3199.1.

Iacono, M. J., J. S. Delamere, E. J. Mlawer, M. W. Shepard, S. A. Clough, and W. D. Collins, 2008: Radiative forcing by longlived greenhouse gases: Calculations with the AER radiative transfer models. J. Geophys. Res., 113, D13103, https://doi.org/ 10.1029/2008JD009944.

Jiménez, P. A., J. Dudhia, J. F. González-Rouco, J. Navarro, J. P. Montávez, and E. García-Bustamante, 2012: A revised scheme for the WRF surface layer formulation. Mon. Wea. Rev., 140, 898-918, https://doi.org/10.1175/MWR-D-11-00056.1.

Judt, F., S. S. Chen, and J. Berner, 2016: Predictability of tropical cyclone intensity: Scale-dependent forecast error growth in high-resolution stochastic kinetic-energy backscatter ensembles. Quart. J. Roy. Meteor. Soc., 142, 43-57, https://doi.org/ 10.1002/qj.2626.

Kain, J. S., 2004: The Kain-Fritsch convective parameterization: An update. J. Appl. Meteor., 43, 170-181, https://doi.org/ 10.1175/1520-0450(2004)043<0170:TKCPAU>2.0.CO;2.

Kam, J., J. Sheffield, and E. F. Wood, 2014: Changes in drought risk over the contiguous United States (1901-2012): 
The influence of the Pacific and Atlantic Oceans. Geophys. Res. Lett., 41, 5897-5903, https://doi.org/10.1002/ 2014GL060973.

Koster, R. D., and Coauthors, 2004: Regions of strong coupling between soil moisture and precipitation. Science, 305, 11381140, https://doi.org/10.1126/science.1100217.

- , and Coauthors, 2006: GLACE: The Global Land-Atmosphere Coupling Experiment. Part I: Overview. J. Hydrometeor., 7, 590-610, https://doi.org/10.1175/JHM510.1.

Krishnamurthy, L., G. Vecchi, R. Msadek, A. Wittenberg, T. Delworth, and F. Zeng, 2015: The seasonality of the Great Plains low-level jet and ENSO relationship. J. Climate, 28, 4525-4544, https://doi.org/10.1175/JCLI-D-14-00590.1.

Kumar, S. V., and Coauthors, 2006: Land information system: An interoperable framework for high resolution land surface modeling. Environ. Modell. Software, 21, 1402-1415, https:// doi.org/10.1016/j.envsoft.2005.07.004.

Maddox, R. A., 1983: Large-scale meteorological conditions associated with midlatitude, mesoscale convective complexes. Mon. Wea. Rev., 111, 1475-1493, https://doi.org/10.1175/15200493(1983)111<1475:LSMCAW > 2.0.CO;2.

Markowski, P., and Y. Richardson, 2010: Mesoscale Meteorology in Midlatitudes. Wiley-Blackwell, $430 \mathrm{pp}$

McCorcle, M. D., 1988: Simulation of surface-moisture effects on the Great Plains low-level jet. Mon. Wea. Rev., 116, 1705-1720, https://doi.org/10.1175/1520-0493(1988)116<1705: SOSMEO $>2.0 . \mathrm{CO} ; 2$.

Means, L. L., 1954: A study of the mean southerly wind maximum in low levels associated with a period of summer precipitation in the Middle West. Bull. Amer. Meteor. Soc., 35, 166-170, https://doi.org/10.1175/1520-0477-35.4.166.

Melillo, J. M., T. Richmond, and G. W. Yohe, 2014: Climate Change Impacts in the United States: The Third National Climate Assessment. U.S. Government Printing Office, 841 pp.

Mitchell, M. J., R. W. Arritt, and K. Labas, 1995: A climatology of the warm season Great Plains low-level jet using wind profiler observations. Wea. Forecasting, 10, 576-591, https://doi.org/ 10.1175/1520-0434(1995)010<0576:ACOTWS $>2.0 . C O ; 2$.

Mooney, P. A., C. Broderick, C. L. Bruyère, F. J. Mulligan, and A. F. Prein, 2017: Clustering of observed diurnal cycles of precipitation over the United States for evaluation of a WRF multiphysics regional climate ensemble. J. Climate, 30, 92679286, https://doi.org/10.1175/JCLI-D-16-0851.1.

Muñoz, E., and D. Enfield, 2011: The boreal spring variability of the Intra-Americas low-level jet and its relation with precipitation and tornadoes in the eastern United States. Climate Dyn., 36, 247-259, https://doi.org/10.1007/s00382009-0688-3.

NCAR, 2017: ARW version 3 model modeling system user's guide. National Center for Atmospheric Research Tech. Doc., NCAR, 443 pp., http://www2.mmm.ucar.edu/wrf/users/docs/ user_guide_V3.9/ARWUsersGuideV3.9.pdf.

NCEI, 2019: Billion-dollar weather and climate disasters: Table of events. NOAA/NCEI, accessed 25 April 2019, https://www.ncdc.noaa.gov/ billions/events.

Parish, T. R., 2017: On the forcing of the summertime Great Plains low-level jet. J. Atmos. Sci., 74, 3937-3953, https://doi.org/ 10.1175/JAS-D-17-0059.1.

— , and L. D. Oolman, 2010: On the role of sloping terrain in the forcing of the Great Plains low-level jet. J. Atmos. Sci., 67, 2690-2699, https://doi.org/10.1175/2010JAS3368.1.

Peters-Lidard, C. D., and Coauthors, 2007: High-performance Earth System modeling with NASA/GSFC's Land Information
System. Innov. Syst. Software Eng., 3, 157-165, https://doi.org/ 10.1007/s11334-007-0028-x.

Reichle, R. H., Q. Liu, R. D. Koster, C. S. Draper, S. P. Mahanama, and G. S. Partyka, 2017: Land surface precipitation in MERRA-2. J. Climate, 30, 1643-1664, https://doi.org/10.1175/ JCLI-D-16-0570.1.

Rotunno, R., J. B. Klemp, and M. L. Weisman, 1988: A theory for strong, long-lived squall lines. J. Atmos. Sci., 45, 463-485, https://doi.org/10.1175/1520-0469(1988)045<0463: ATFSLL $>2.0 . \mathrm{CO} ; 2$.

Santanello, J. A., and Coauthors, 2018: Land-atmosphere interactions: The LoCo perspective. Bull. Amer. Meteor. Soc. 99, 1253-1272, https://doi.org/10.1175/BAMS-D-17-0001.1.

Schubert, S. D., M. J. Suarez, P. J. Pegion, R. D. Koster, and J. T. Bacmeister, 2004: Causes of long-term drought in the U.S. Great Plains. J. Climate, 17, 485-503, https://doi.org/10.1175/ 1520-0442(2004)017<0485:COLDIT>2.0.CO;2.

Shapiro, A., and E. Fedorovich, 2010: Analytical description of a nocturnal low-level jet. Quart. J. Roy. Meteor. Soc., 136, 12551262, https://doi.org/10.1002/qj.628.

- - , and S. Rahimi, 2016: A unified theory for the Great Plains nocturnal low-level jet. J. Atmos. Sci., 73, 3037-3057, https://doi.org/10.1175/JAS-D-15-0307.1.

Shutts, G. J., 2005: A kinetic energy backscatter algorithm for use in ensemble prediction systems. Quart. J. Roy. Meteor. Soc., 131, 3079-3102, https://doi.org/10.1256/qj.04.106.

Skamarock, W. C., and Coauthors, 2008: A description of the Advanced Research WRF version 3. NCAR Tech. Note NCAR/TN-475+STR, 113 pp., https://doi.org/10.5065/ D68S4MVH.

Song, H., C. R. Ferguson, and J. K. Roundy, 2016: Landatmosphere coupling at the Southern Great Plains Atmospheric Radiation Measurement (ARM) field site and its role in anomalous afternoon peak precipitation. J. Hydrometeor., 17, 541-556, https://doi.org/10.1175/JHM-D-15-0045.1.

Song, J., K. Liao, R. L. Coulter, and B. M. Lesht, 2005: Climatology of the low-level jet at the southern Great Plains Atmospheric Boundary Layer Experiments site. J. Appl. Meteor., 44, 15931606, https://doi.org/10.1175/JAM2294.1.

Thompson, G., P. R. Field, R. M. Rasmussen, and W. D. Hall, 2008: Explicit forecasts of winter precipitation using an improved bulk microphysics scheme. Part II: Implementation of a new snow parameterization. Mon. Wea. Rev., 136, 5095-5115, https://doi.org/10.1175/2008MWR2387.1.

Uccellini, L. W., 1980: On the role of upper tropospheric jet streaks and leeside cyclogenesis in the development of low-level jets in the Great Plains. Mon. Wea. Rev., 108, 1689-1694, https://doi.org/ 10.1175/1520-0493(1980)108<1689:OTROUT>2.0.CO;2.

__ , and D. R. Johnson, 1979: The coupling of upper and lower tropospheric jet streaks and implications for the development of severe convective storms. Mon. Wea. Rev., 107, 682-703, https://doi.org/10.1175/1520-0493(1979)107<0682: TCOUAL $>2.0 . \mathrm{CO} ; 2$.

Walters, C. K., and J. A. Winkler, 2001: Airflow configurations of warm season southerly low-level wind maxima in the Great Plains. Part I: Spatial and temporal characteristics and relationship to convection. Wea. Forecasting, 16, 513-530, https://doi.org/ 10.1175/1520-0434(2001)016<0513:ACOWSS > 2.0.CO;2.

Wang, S., and T. Chen, 2009: The late-spring maximum of rainfall over the U.S. central plains and the role of the low-level jet. J. Climate, 22, 4696-4709, https://doi.org/10.1175/2009JCLI2719.1.

Wexler, H., 1961: A boundary-layer interpretation of the low-level jet. Tellus, 13, 368-378, https://doi.org/10.3402/tellusa.v13i3.9513. 
Whiteman, C. D., X. Bian, and S. Zhong, 1997: Low-level jet climatology from enhanced rawinsonde observations at a site in the southern Great Plains. J. Appl. Meteor. 36, 1363-1376, https://doi.org/10.1175/1520-0450(1997)036<1363: LLJCFE $>2.0 . C O ; 2$.

Yang, S., X. Ding, D. Zheng, and Q. Li, 2007: Depiction of the variations of Great Plains precipitation and its relationship with tropical central-eastern Pacific SST. J. Appl. Meteor. Climatol., 46, 136-153, https://doi.org/10.1175/JAM2455.1.
Yu, L., S. Zhong, J. A. Winkler, D. L. Doubler, X. Bian, and C. K. Walters, 2017: The inter-annual variability of southerly lowlevel jets in North America. Int. J. Climatol., 37, 343-357, https://doi.org/10.1002/joc.4708.

Zhong, S., J. Fast, and X. Bian, 1996: A case study of the Great Plains low-level jet using wind profiler network data and a high-resolution mesoscale model. Mon. Wea. Rev., 124, 785-806, https://doi.org/10.1175/1520-0493(1996)124<0785: ACSOTG $>2.0 . \mathrm{CO} ; 2$. 